\title{
On the Routines of Wild-Type Silk Fibroin Processing Toward Silk-Inspired Materials: A Review
}

\author{
Vadim Volkov, Ana V. Ferreira, Artur Cavaco-Paulo*
}

For years, silk fibroin of a domestic silkworm, Bombyx mori, has been recognized as a valuable material and extensively used. In the last decades, new application fields are emerging for this versatile material. Those final, specific applications of silk dictate the way it has been processed in industry and research. This review focuses on the description of various approaches for silk downstream processing in a laboratory scale, that fall within several categories. The detailed description of workflow possibilities from the naturally found material to a finally formulated product is presented. Considerable attention is given to (bio-) chemical approaches of silk fibroin transformation, particularly, to its enzymedriven modifications. The focus of the current literature survey is exclusively on the methods applied in research and not industry.

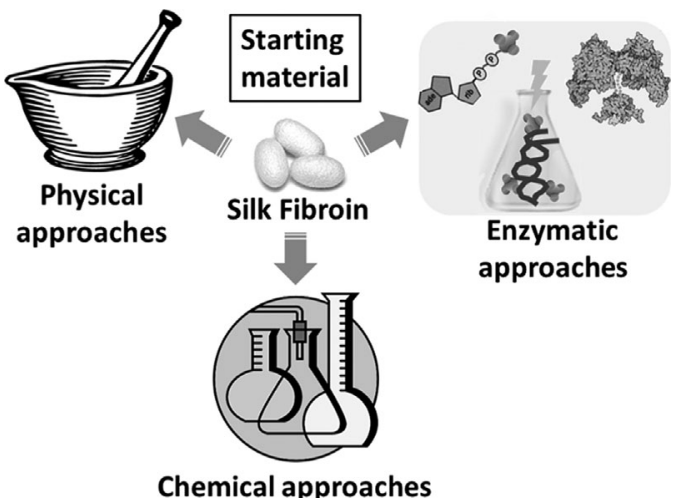

\section{Silk Fibroin, a Protein, and a Biopolymer}

Throughout the years of research a vast amount of information concerning silk diversification is available. Hence, the scope of the current review encompasses only wild type fibrous protein, and not its genetically engineered (chimeric) deviations ( ${ }^{[1]}$ and references within). Hybrid materials, for instance, fibroin-based coatings on various metal $^{[2]}$ and polymeric ${ }^{[3]}$ supports or micro-fabricated meta-material silk-metal composites ${ }^{[4,5]}$ will not be discussed. Silk fibroin (SF) is a natural protein polymer, produced by some of Lepidoptera species, such as silkworms and butterflies. ${ }^{[6]}$ Depending on its source and biological function, the silk composition, structure, and properties may differ significantly. ${ }^{[7]}$ One of the most characterized silks come from the silkworm B. mori due to its history of

Prof. A. Cavaco-Paulo, V. Volkov, A. V. Ferreira

Centro de Engenharia Biológica (CEB), Universidade do Minho,

Campus de Gualtar 4710-057, Braga, Portugal

E-mail: artur@deb.uminho.pt

Fax: +351253604 429 domestication, ${ }^{[8]}$ uses in textile industry and medicine. ${ }^{[7]}$ Owing to biocompatible and mechanical properties of $S F$, its use has been increasing dramatically in biotechnology and biomedical areas. ${ }^{[6]}$ Attempts are being made to control the silk fibroin-based technology from scratch and to promote its up-scaling from the laboratory to industrial scale, by developing methods and protocols suitable for biotechnology and sustainable manufacturing. ${ }^{[9]}$

Wild-type silkworm SF, consists of two different proteinaceous parts: the structural fibrous protein and sericin, a glue-like protein that covers the fibroin molecules into larger fiber tread. ${ }^{[8]}$ "Wild-type" protein in the particular context is meant to be a naturally found (or secreted), as opposed to the recombinant one. ${ }^{[10]}$ Different aspects of SF structure, composition, and MW have been extensively discussed elsewhere. ${ }^{[11-17]}$

A number of SF structures have been reported (Figure 1 and see ref. ${ }^{[18]}$ ): the water-soluble state (Silk I), the crystalline silk (Silk II), and an air/water interface orientation (Silk III). ${ }^{[12]}$ Silk I is ordinarily observed in the silkworm glands, ${ }^{[19]}$ it contains random-coil and amorphous regions. ${ }^{[20]}$ Silk I is unstable to mechanical or 


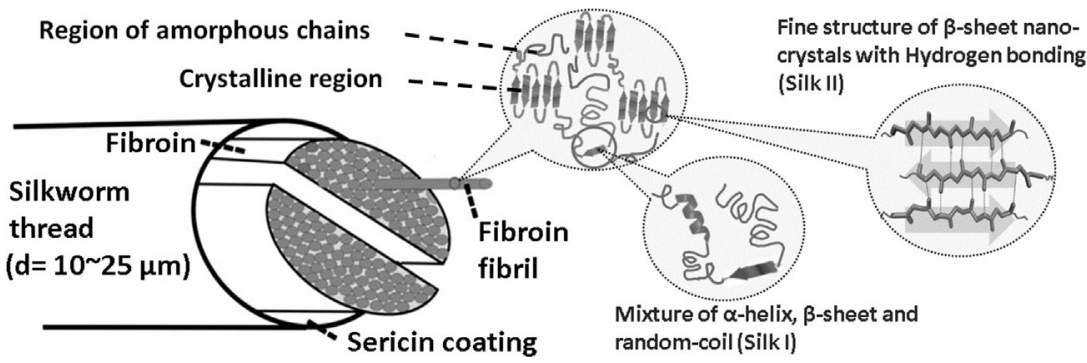

Figure 1. Schematic representation of the deduced SF structure. Insets show the fibri overall structure and the fine $\beta$-sheet antiparallel alignment of SF polypeptide chains.

shear stress, ${ }^{[8]}$ thus it converts to antiparallel $\beta$-sheet, i.e., Silk II. ${ }^{[12]}$ Iizuka and Yang have shown that Silk II structure can also dissolve without precipitation in mixed solvents of water and methanol or dioxane. ${ }^{[12,21]}$ For the Silk II structure, the antiparallel $\beta$-sheets, established by hydrogen bonds between the opposite Gly and Ala side chains were proposed. ${ }^{[8,12,22]}$ The crystalline conformation leads to a thermodynamically stable structure, preventing spontaneous separation of molecules ${ }^{[8]}$ and water-based dissolution, including solvents of mild acid and alkaline composition, and some chaotropes. ${ }^{[12]}$

Finally, the crystal Silk III structure involves a hexagonal arrangement of silk molecules in a threefold helical chain conformation. This structure causes the separation of Ser and Ala residues, allowing fibroin to act as a surfactant at the air-water interface. ${ }^{[23]}$

\section{Manipulating Silk Fibroin: Initial Processing and Physical Treatments of Silk-Derived Materials}

The current chapter describes various possibilities of silk treatments that can be perceived as a preparation step(s) for its further modifications, or, in some cases, they can result in a finally formulated product. Examples include, but are not limited to, porous materials obtained by lyophilization, or hydrogels acquired from gelation. Figures 2 and 3 summarize the main workflow routines, discussed below.

\subsection{Degumming of Silk Fibroin}

As a starting point, the stifled cocoons (devoid of pupae) need to be de-gummed. The degumming process is a sericin coating removal and results in cocoon decomposition, raw silk fiber mass is obtained. Several ways of degumming have been reviewed before, ${ }^{[24,25]}$ of which boiling in $0.02 \mathrm{M}$ sodium carbonate, $\mathrm{Na} 2 \mathrm{CO} 3$, for $30 \mathrm{~min}$ is commonly used. ${ }^{[26]}$ Recently, the use of a recombinant cocoonase enzyme from $B$. mori source (BmCoc) in the silk degumming process was reported. ${ }^{[27]}$ Sericin removal pursues two goals: it abolishes biocompatibility issues of subsequent silk related viability of cells, cultivated on SF-based materials ${ }^{[34]}$ are also affected. Prolonged degumming in harsh conditions results in degradation of SF into lower MW fragments influencing cell functioning. Considering this, possible side effects of different degumming protocols should be taken into account when designing a biocompatible material.

\subsection{Introduction to the Processing: Modifications of Intact Silk Fiber}

Sericin-free silk can be used directly, in a solid state, or preferably be dissolved, as an initial step of material fabrication. SF can be used directly for fabrication of tetracycline-loaded sutures, ${ }^{[35]}$ cross-linked silk-collagen, ${ }^{[36]}$ and silk-gelatine ${ }^{[37]}$ scaffolds, poly lactic-co-glycolic acid (PLGA)-coated and bFGF-releasing bio-hybrid materials $^{\left[{ }^{[3]}\right.}$ twisted silk cords $^{[26]}$ or silk-based hollow tubes. ${ }^{[39]}$ The common aspect of these approaches is the preparation of braided, knitted, or yarned fibrous structures that serve as a frame for further production. In some cases, this frame of future material can be elaborated prior to degumming, ${ }^{[40,41]}$ still most of all the subsequent treatments are performed after sericin removal step. Bromination ${ }^{[42]}$ and chlorination ${ }^{[43]}$ of SF fabrics on Ser residues with halogen derivatives were reported, with yields of Ser conversion of 10 and 30\%, respectively. Raw silk filaments can also be modified by the nano-TiO2 and chitosan dispersion system via cross-linking reactions of citric acid and maleic anhydride. ${ }^{[4]}$ Modified SF-exhibited rougher surface and increased crystallinity than that of the original fibroin, while the fundamental crystal structure remained intact. UV irradiation is another way of altering SF-it can be used as modeling of ageing processes within the biopolymer by Tyr photo-oxidation and cross-linking of Tyr and other residues $^{[45]}$ (Figure 4). Additional morphological effects, seen as roughening, were observed on the surface of irradiated silk samples. ${ }^{[46,47]}$ The roughening, caused by forming of nanopores, was accompanied by slight degradation and decrease in mechanical properties. Aspects of free radical formation in SF were further elucidated by electron spin resonance (ESR) studies. ${ }^{[48]}$ Silk fabrics, 


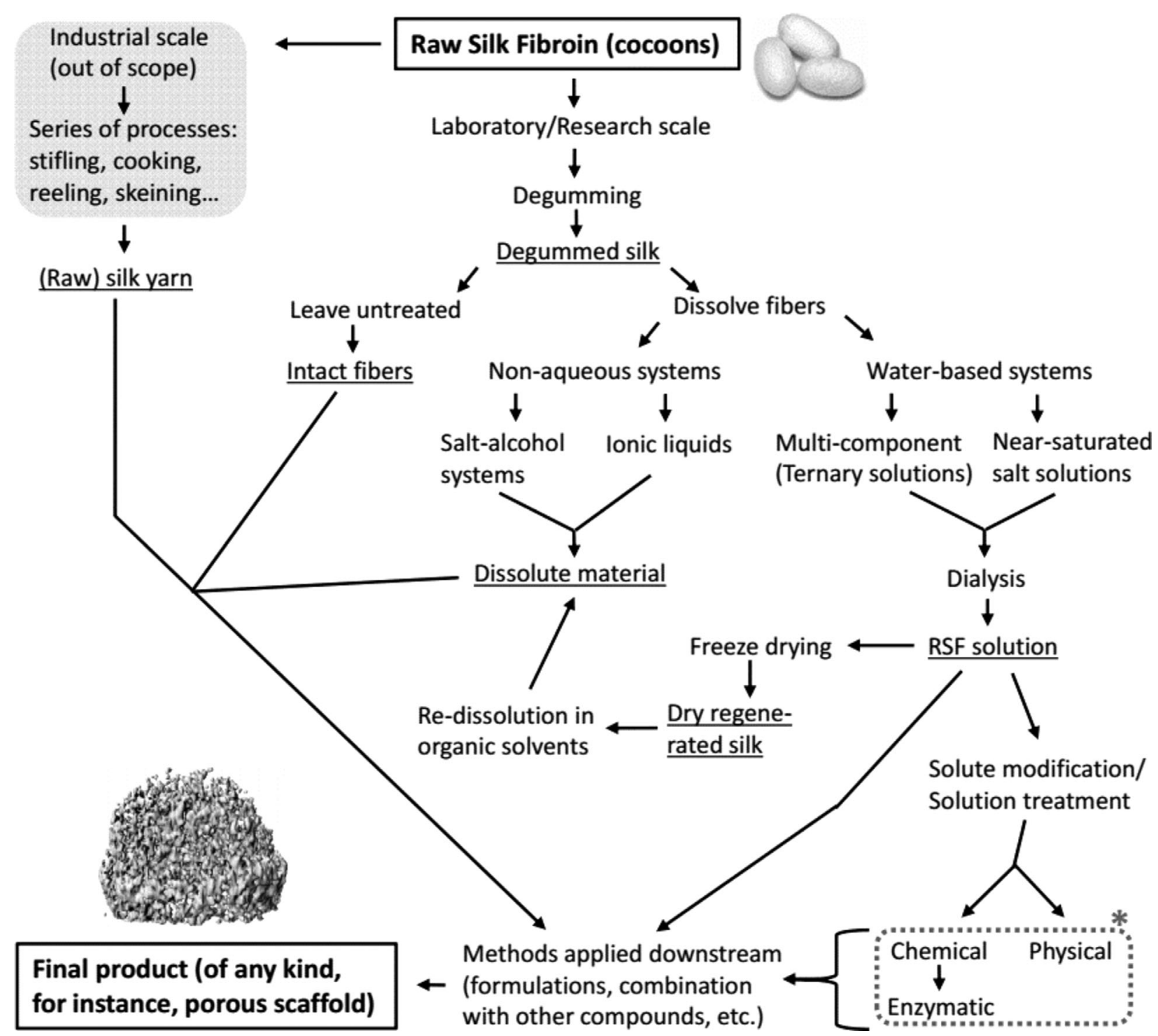

Figure 2. Outline of the main steps in possible silk pre-treatment protocols. In this context, the "pre-treatment" means any procedures, aiming to prepare the raw fibrous material for a downstream processing. The key points are raw silk fibroin in its cocoon form and the final product. Underlined phrases designate (intermediate) products. Arrows designate the workflow direction. Example images of raw silk and final product are not to scale. Methods designated by asterisk are the scope of extended revision and are depicted in Figure 3.

oxidized by ozone, displayed increase in yellowness, moreover, a decrease in breaking strength and elongation, weight, and flexibility was noticed. ${ }^{[49]}$ LBL polymers of poly-(allylamine hydrochloride) and poly-(acrylic acid), deposited on SF fabrics, were further enhanced by crosslinking with activated heparin. By doing this, the hemocompatibility of the resulting material was improved. ${ }^{[50]}$

\subsection{Fibroin Dissolution Techniques}

The more promising and common way of using SF in material engineering is through its dissolution and working with solubilized fibroin. Due to its tightly packed structure, $\mathrm{SF}$ is insoluble in most solvents, used to dissolve polymers for biological applications, and in water. To dissolve SF, two main concentrated salt-based systems are employed: nonaqueous and aqueous. The first includes calcium nitrate in methanol, $\mathrm{Ca}(\mathrm{NO} 3)$ 2- $\mathrm{MeOH} ;{ }^{[51]}$ lithium bromide in ethanol, LiBr-EtOH; ${ }^{[52]}$ calcium chloride in formic acid, $\mathrm{CaCl}-\mathrm{FA} ;{ }^{[53]}$ compounds of methylimidazolium group (so-called ionic liquids), ${ }^{[54,55]}$ and some others. Those acquired solutions are further utilized without dialysis. The second, water-based, system encompasses lithium or sodium thiocyanates, Li- or $\mathrm{Na}-\mathrm{SCN} ;{ }^{[56,57]}$ lithium bromide,

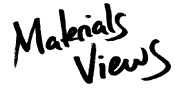

www.MaterialsViews.com
Macromol. Mater. Eng. 2015, 12, 1199-1216

(c) 2015 WILEY-VCH Verlag GmbH \& Co. KGaA, Weinheim 


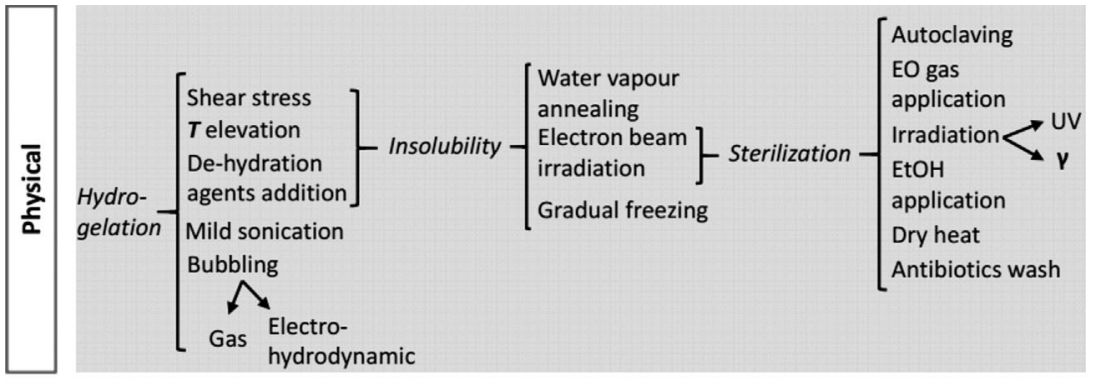

Gas plasma treatment

\section{Hydrolysis}

Sono-chemistry

Tyr oxidation / crosslinking Esterification / MOl-assisted
Direct modification of

a.a. side chains

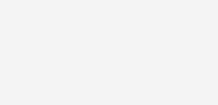

Crosslinking / coupling / grafting

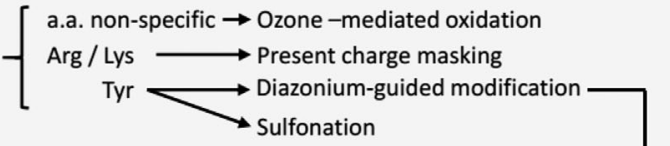

Cyanuric chloride-assisted imidization reactions Reductive alkylation EDC/NHS-assisted UV-assisted "Click chemistry" method Other cross-linkers (genipin, gluteraldehyde)

Segmented block copolymer synthesis

Crosslinking (HRP)

Phosphorylation (PKA)

Tyr oxidation (MT) $\longrightarrow$ Subsequent grafting of molecules of interest

ALP-mediated mineralization

a-chemotrypsin

Micro-gel synthesis

Material degradation

$\left\{\begin{array}{l}\text { Protease XIV / Proteinase K } \\ \text { Other proteases (Alcalase / TrP }\end{array}\right.$

Other proteases (Alcalase / Trypsin / Pepsin)

[Fibroinolytic enzyme of B.thermoruber YAS-1]

Figure 3. Detailed representation of the three (pre-) treatment directions for silk fibroin: physical, chemical, and enzymatic. Arrows designate different processing options. For detailed description, see text.

$\mathrm{LiBr}^{[26]}$ or salts with similar nucleophilicity of the anion. ${ }^{[58]}$ Special cases may dictate the usage of cuprammonium hydroxide (cuoxam), for example, when SF/cellulose blends are prepared. ${ }^{[59]}$ Ternary aqueous systems of calcium chloride or lithium bromide and ethanol $\mathrm{CaCl} 2 / \mathrm{LiBr}-$ EtOH-H2O ${ }^{[60,61]}$ are also known. The dissolution step is followed by a dialysis in water/appropriate buffer for salt removal. For water-based system, a $9.3 \mathrm{M}$ aqueous $\mathrm{LiBr}$ at $60^{\circ} \mathrm{C}, 4 \mathrm{~h}$ incubation is typically used. ${ }^{[26]}$ Moreover, some organic systems with residual water content are known, similar to $N$-methyl morpholine $N$-oxide (MMNO) hydrate, where the water significantly influences the ability of the compound to act as a solvent. ${ }^{[62]}$ Whether prepared from aqueous or non-aqueous solution systems, the finally elaborated materials are considered as obtained from regenerated silk fibroin (RSF).

\subsection{Initial Processing. The Handling of an RSF Solution Fibroin}

With the RSF being at stock, a workflow can generally be split in three directions: freeze-drying and working with lyophilized material, solution alteration (either physically, chemically, or both), or its direct subsequent processing. The latter option means that an RSF solution is used "as is" in the downstream application, whilst the first two approaches imply some preceding step(s) before RSF use in that successive application. Direct processing is comprised of RSF coatings of previously elaborated materials, either by layer-bylayer (LBL) method or simple soaking (reviewed in refs. ${ }^{[63,64]}$ ); blending with other compounds of interest, including their bulk loading, as reviewed in ref. ${ }^{[65]}$ Mineralization of prepared silk-based scaffolds by rounds of calcium phosphate (apatite) deposition is also possible. ${ }^{[66-69]}$ Recently, the effects of different foetal bovine serum (FBS) types on mineralization of 3D silk-based scaffolds were elucidated. Dependent on FBS type, spontaneous mineralization was observed in some scaffolds. ${ }^{[70]}$ Other alternatives include dipped or spun silk tubes and vortexed hydrogels, those preparations are detailed in ref. ${ }^{[26]}$ Metastable silk nanoparticles, prepared by repeating drying-dissolving process of aqueous RSF solution, are also

available. ${ }^{[71]}$

Freeze-drying may be used as a final product formulation, ${ }^{[72,73]}$ however, usually is used as an intermediate step. Hence, the lyophilized RSF can be later re-dissolved in various solvents like hexafluoro-2-propanol (HFIP), hexafluoro-acetone (HFA), formic, or trifluoro-acetic acids, for the fabrication of (electro-) spun nanofibers, scaffolds, or casted films. ${ }^{[74-77]}$ Some 3D scaffolds (or sponges) can be produced with the help of introduced porogens (typically $\mathrm{NaCl}$ with subsequent salt leaching ${ }^{[78,79]}$ ), or with the help of modulators for a forming fine structure conformation like glycerol, ${ }^{[80]}$ or fabric reinforcing technique ${ }^{[81]}$ and not solely by freeze-drying. At the stage following redissolution, RSF is often blended with other compounds 
A

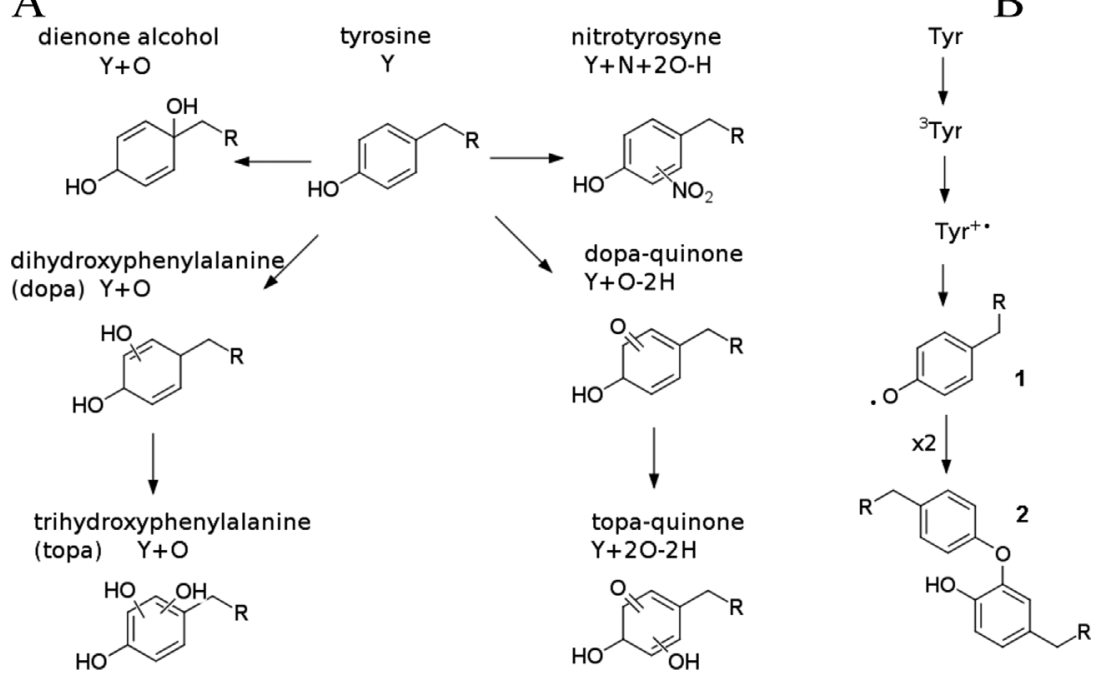

Figure 4. Proposed pathways of tyrosine photo-oxidation. (A) Variety of final products. (B) Specific pathway toward dimerization (via C-O or C-C linkages) to yield di-tyrosine product. 1-tyrosyl radical, 2-a C-O linked isomer of a di-tyrosine cross-link. Images adapted from refs. ${ }^{[45]}$ and, ${ }^{[224]}$ respectively.

of interest; the final material formulation depends on the current need. Similarly to the direct processing and after the formulation, SF-derived devices may be coated by simple deposition of molecules of biological significance like vascular endothelial growth factor (VEGF) and/or laminin, ${ }^{[82]}$ BMP-2. ${ }^{[83]}$ Numerous examples of RSF-based scaffolds, ${ }^{[84]}$ blended $^{[85,86]}$ and regenerated ${ }^{[87,88]}$ films, and spun nanofibers, ${ }^{[89]}$ along with their features and fabrication methods, have been reported. The reason why raw SF is not exposed for dissolution directly by some solvents (especially organic: HFIP, HFA) stems from the fact that fibroin can be efficiently dissolved only after its preliminary activation. ${ }^{[58]}$ Such activation is the process of silk primary dissolution by near-saturated solutions of chaotropes, as described before. For instance, attempt to dissolve raw-degummed SF in HFIP took 5 months for its completion. ${ }^{[90]}$

\subsection{Advanced Processing. Treatments of an RSF Solution and RSF-Derived Materials}

Solution alteration treatments, mentioned in the previous part, actually open an immense field of possibilities for material design and development and thus demand a special description. The treatments can roughly be divided in two: physical and chemical, that are a minor and major part of all possibilities, respectively. In turn, the chemical modifications can be traditional, non-enzymatic, reactions, or be catalyzed by enzymes. For the summary of methods, presented below, refer to Figure 3. Chemical modifications will be discussed separately in the next chapter.
Constrained amount of physical manipulations, applied to RSF solution, aim three goals-hydrogels production (gelation), induction of aqueous insolubility of elaborated materials, or sterilization. Gelation is commonly induced by shear stress (vortexing), ${ }^{[91]}$ mild sonication $^{[92]}$ (also possible in combination with other natural polymers like chitosan $^{[93]}$ or agarose ${ }^{[94]}$, or elevated temperature. ${ }^{[95]} \mathrm{K}^{+}$or $\mathrm{Ca}^{2+}$ ions addition also facilitates hydrogel formation at decreased $\mathrm{pH}$ of RSF. ${ }^{[92,95]}$ Polyethylene oxide (PEO), ${ }^{[95]}$ poloxamer 407, ${ }^{[96]}$ polyalcohols (glycerol, polyethylene glycol, and similar compounds ${ }^{[97-100]}$, sodium dodecyl sulfate (SDS) ${ }^{[101]}$ additives are known as gelation promoters. Due to their hydrophilicity, PEO, poloxamer 407, and polyalcohols dehydrate RSF, causing its hydrophobic self-aggregation, while sodium dodecyl sulfate (SDS) causes RSF to form mixed micelle particles. Those SDS/RSF micelles serve as nucleation centers for subsequent hydrophobic agglomeration of silk. Gel formation may also be promoted by increasing silk concentration in solution. ${ }^{\left[{ }^{92,102]}\right.}$ Recently, $\mathrm{CO}_{2}$-assisted synthesis of RSF hydrogels by gas bubbling and $3 \mathrm{D}, 2 \mathrm{D}$, or standalone RSF structures by electrohydrodynamic (EHD) bubbling were reported. ${ }^{[103,104]}$

The virtual insolubility of (R)SF-derived materials in aqueous media is a crucial property at the end of production, since in most cases their application will involve contact with water or water-based solutions. It is directly related to crystallinity of a fibroin. Common practices of crystallinity induction include methanol treatments ${ }^{[105-107]}$ or increased temperature application $^{[106]}$ (both done for already produced materials) and altering of ionic balance ${ }^{[95,108]}$ (for the "liquid step" of a fabrication; casted material will be water-insoluble upon solvent evaporation). However, saturated salt solution may be also used for crystallinity augmentation of prepared, dry product formulation, as silk microspheres. ${ }^{[109]}$ Shear stress during SF spinning in the glands of insects ${ }^{[110]}$ may be mimicked to some extent ex vivo and spun silk fibers, bearing characteristic silk II structure, may be obtained. ${ }^{[111]}$ Sometimes the above-described means for rendering materials that are water-stable are less preferable. Water vapor annealing ${ }^{[112-114]}$ and gradual freezing (with or without lyophilization) ${ }^{[115,116]}$ represent milder conditions for the same purpose.

It can be seen that such treatments as temperature augmentation and lyophilization, despite their difference, can serve two goals, relying on mechanistically close

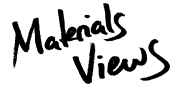

www.MaterialsViews.com
Macromol. Mater. Eng. 2015, 12, 1199-1216

(c) 2015 WILEY-VCH Verlag GmbH \& Co. KGaA, Weinheim 
phenomena-complete or partial gelation and decreased solubility in aqueous media. In this context, it is interesting to mention that sterilization, generally performed on formulated material, ${ }^{[117,118]}$ may be applied to RSF solutions. As reported, autoclaving of RSFs of varying concentrations $(4,8$, and $12 \% \mathrm{w} / \mathrm{v})$ "did not significantly change the sonication parameters used and the related gelation times." ${ }^{[92]}$ Several reports assess the possibilities for sterilization of SF-based materials. Methods like immersion in $70 \%$ ethanol solution, autoclaving (steam), ethylene oxide (EO), ultraviolet (UV) or $\gamma$ radiation application, dry heat and antibiotics mix wash were investigated. Studies agree that autoclaving considerably affects mechanical properties of silk, whilst EO has very little influence. ${ }^{[119-121]}$ Eventual darkening of steamsterilized silk was observed. ${ }^{[121]}$ Recent examination confirms the time-dependent thermal degradation and partial conformational changes of silk structure in the course of autoclaving. ${ }^{[122]}$ Ethanol had adverse mechanical effects on differently formulated materials, ${ }^{[120]}$ but is not considered as appropriate sterilization agent, but rather a disinfection mean. ${ }^{[119]}$ Both UV and $\gamma$ irradiations retained the original conformational structure of elaborated devices, ${ }^{[120,121]}$ whereas $\gamma$ radiation caused silk degradation in a dose-dependent manner. ${ }^{[121]}$ Similarly to ethanol, UV was considered a way of disinfection. ${ }^{[120]}$ Dry heat caused partial destruction and shrinkage of porous scaffolds, while antibiotics mix caused no effect. ${ }^{[119]}$ Interesting outcomes were obtained when RSF cast films were subjected to electron beam irradiation at a dose range between 0 and $150 \mathrm{kGy} .{ }^{[123]}$ Along with changes in crystalline structure and thermal stability, antibacterial activity of films against both gram-positive and -negative bacteria has increased. The reported increase was dosedependent. Summarizing, sterilization is another important aspect in the total workflow of silk-based materials production, and some sterilization methods may serve additional goals as crystallinity and water-insolubility inductions.

\section{Manipulating Silk Fibroin: Chemical and Biochemical Approaches of RSF Functionalization}

Chemical ways of treating silk represent additional and optional level of complexity that may be employed during production, if necessary. In most cases, the researches wish to customize a final product, rendering (bio-) chemistry as indispensable. Chemical approaches applicable to RSF can be roughly divided into three categories: surface modification only (leaving the material bulk intact), modification of entire material (typically in the pre-formulation stage), and the sonochemical methods. Biochemical approaches constitute surface or bulk material modifications. The third chapter presents a detailed overview of the aforementioned statements. Figure 3 summarizes the main workflow routines, discussed below.

\subsection{Chemical Approaches}

Surface modification includes gas plasma treatments for tailoring hydro-phobicity or hydro-philicity, ${ }^{[124]}$ improving cytocompatibility, ${ }^{[125]}$ and modulating cell attachment. ${ }^{[126]}$ It was postulated that the ionized plasma particles are incapable of penetrating into the depth of textile materials. ${ }^{[127]}$ A sophisticated system, where RSF films are initially aminated by ammonia, $\mathrm{NH}_{3}$ and later covalently sulfonated by sulfur dioxide, $\mathrm{SO}_{2}$ plasma treatments was reported. ${ }^{[128]}$ UV irradiation can be used for conferring hydrophilicity to RSF-based films. ${ }^{[129]}$ Recently, UV-mediated cross-link blends of RSF and chitosan were reported. ${ }^{[130]}$

Other strategies, described below, are applicable to both solid and aqueous forms of SF. A research by Sofia et al. ${ }^{[131]}$ on functionalization of SF-based material with peptides or proteins of interest by means of 1-ethyl-3-(dimethylaminopropyl) carbodiimide (EDC)/ $N$-hydroxysuccinimide (NHS) coupling chemistry was later highly exploited for decorating films and matrices ${ }^{[132-135]}$ and porous scaffolds ${ }^{[136]}$ with Arg-Glu-Asp (RGD, cell adhesion receptors recognition) sequence. Additional examples, among many, include the production of composed elastin/silk/hyaluronan materials, ${ }^{[137]}$ immobilization of Horseradish peroxidase enzyme on the surface of scaffolds ${ }^{[138]}$ or solubilized fibroin attachment to poly(d,l-lactic acid) made films. ${ }^{[139]}$ The approach relies on covalent bond formation between activated $\gamma$-carboxylic groups of Asp and Glu in SF and a primary amine target, typically $\varepsilon-\mathrm{NH}_{2}$ group of Lys. ${ }^{[140]}$ Together Asp and Glu constitute $\approx 1 \%$ of all fibroin molecule's amino acids, yet also $\approx 0.23 \%$ of Lys is present in the polypeptide chains, ${ }^{[14]}$ so that SF self-cross-linking by-products may be formed along with the intended conjugates. The same statement is true regarding any polypeptide to be coupled, possessing both free carboxylic and amino groups, yet this issue is for most disregarded in the cited examples of the previous paragraph, except for one. ${ }^{[138]}$ Other potentially unwanted effects may be introduced to the molecules being coupled via EDC/NHS reaction, ${ }^{[141]}$ like alteration of net charge, conformation, or activity (in case of enzymes).

In spite of the mentioned difficulties, chemical modifications of SF solutions or surfaces of formulated SFbased solid devices, based on carbodiimide chemistry, are quite common. Yet, to overcome some of the drawbacks, a copper (I)-catalyzed azide-alkyne cycloaddition (CuAAC, commonly referred to as "click chemistry") was proposed for SF enhancement ${ }^{[142]}$ (Figure 5). Other coupling 


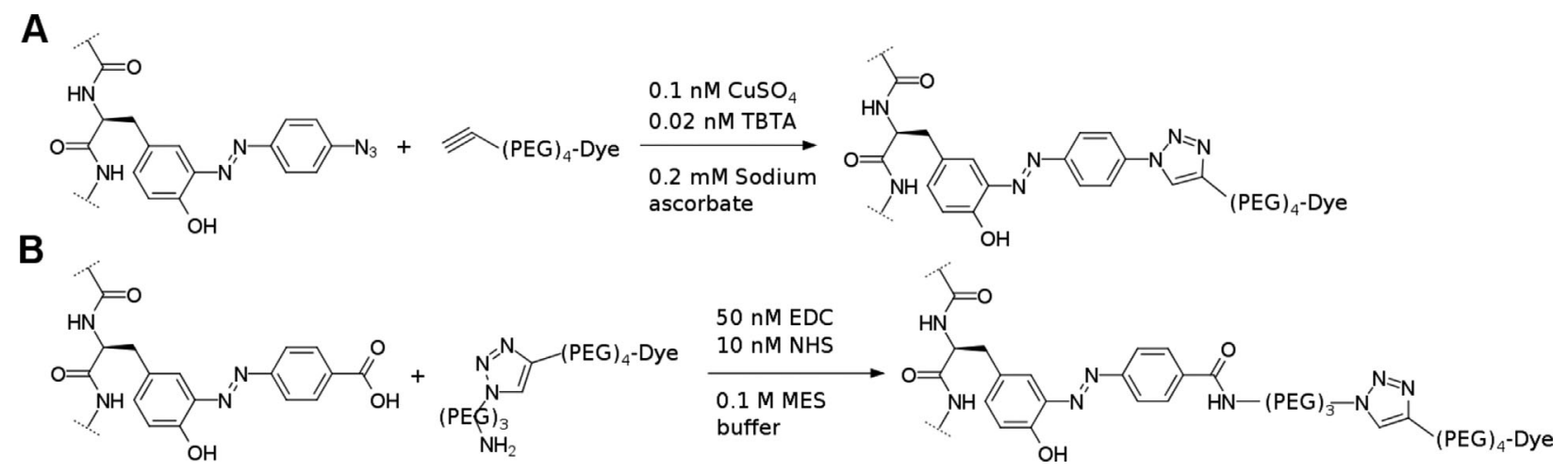

Figure 5. Reaction scheme detailing the synthesis of SF conjugates with the molecules of interest by (A) CuAAC or (B) EDC/NHS chemistry.

Figure taken from ref. ${ }^{[142]}$

possibilities are known, for instance cyanuric chlorideassisted attachment of preliminary activated PEG molecules, ${ }^{[143]}$ lactose derivatives, ${ }^{[144]}$ and $N$-acetyl-chito-oligosaccharides ${ }^{[145]}$ to the Tyr side chain of silk (Figure 6). 2Methacryloyloxyethyl isocyanate (MOI)-assisted addition of terminal vinyl groups to $\mathrm{OH}-\mathrm{NH}_{2}$ - and $\mathrm{COOH}$ - bearing amino acids side chains, followed by the grafting of 2methacryloyloxyethyl phosphorylcholine (MPC) is also known $^{[146]}$ (Figure 7). The aim of the above-mentioned approach is to derivatize silk fabric, decreasing the adhesion of blood platelets. In that sense, a non-thrombogenic material can be elaborated. Moreover, genipin- and glutaraldehyde-assisted linking reactions of elastin ${ }^{[147]}$ and insulin, ${ }^{[148]}$ respectively, to the silk fibroin were described (Figure 8). Using genipin, silk molecules can be cross-linked with hydroxybutyl chitosan, thus improving the mechanical properties of the resulting material and rendering it less cytotoxic. ${ }^{[149]}$ Blended SF-starch-chitosan matrixes, using a non-toxic conjugation method of reductive alkylation chemistry, were successfully prepared and showed high cytocompatibility toward Sarcoma osteogenic (SaOS-2) cells. ${ }^{[150]}$ Cell proliferation could be modulated by changing fibroin/chitosan ratio during the matrix preparation.

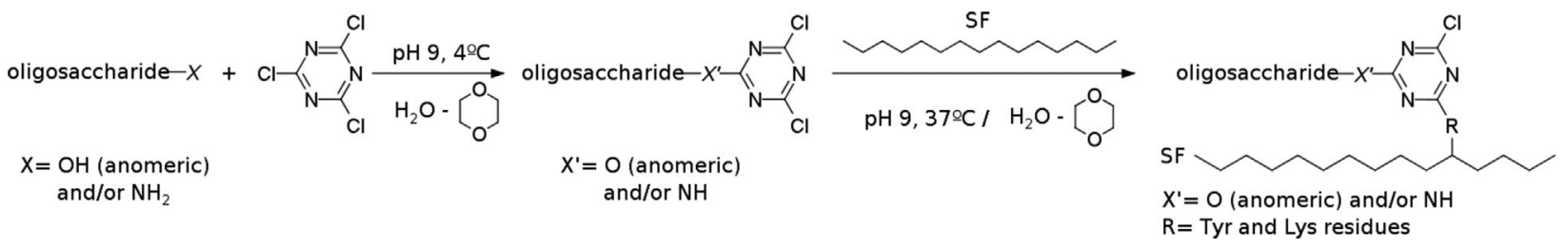

Figure 6. Chemical modification of SF with cyanuric chloride-activated oligosaccharides. Figure adapted from ref. ${ }^{[144]}$

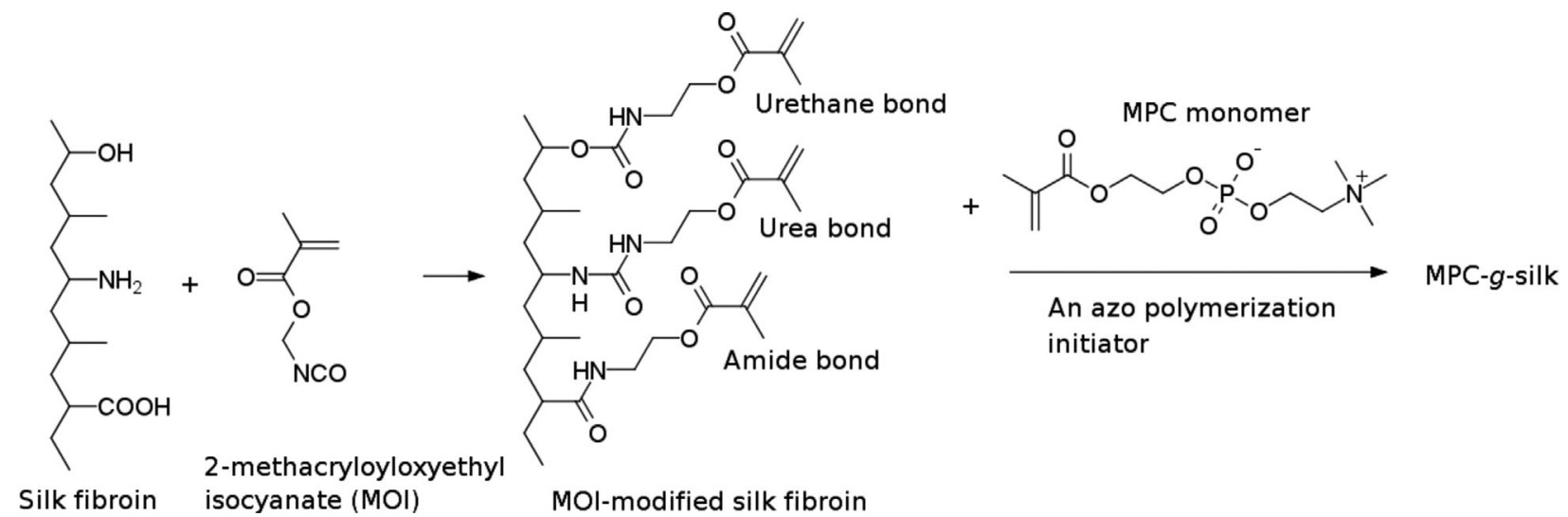

Figure 7. Chemical modification of SF with cyanuric chloride-activated oligosaccharides. Figure adapted from ref. ${ }^{[144]}$

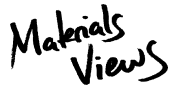

www.MaterialsViews.com
Macromol. Mater. Eng. 2015, 12, 1199-1216

(c) 2015 WILEY-VCH Verlag GmbH \& Co. KGaA, Weinheim 


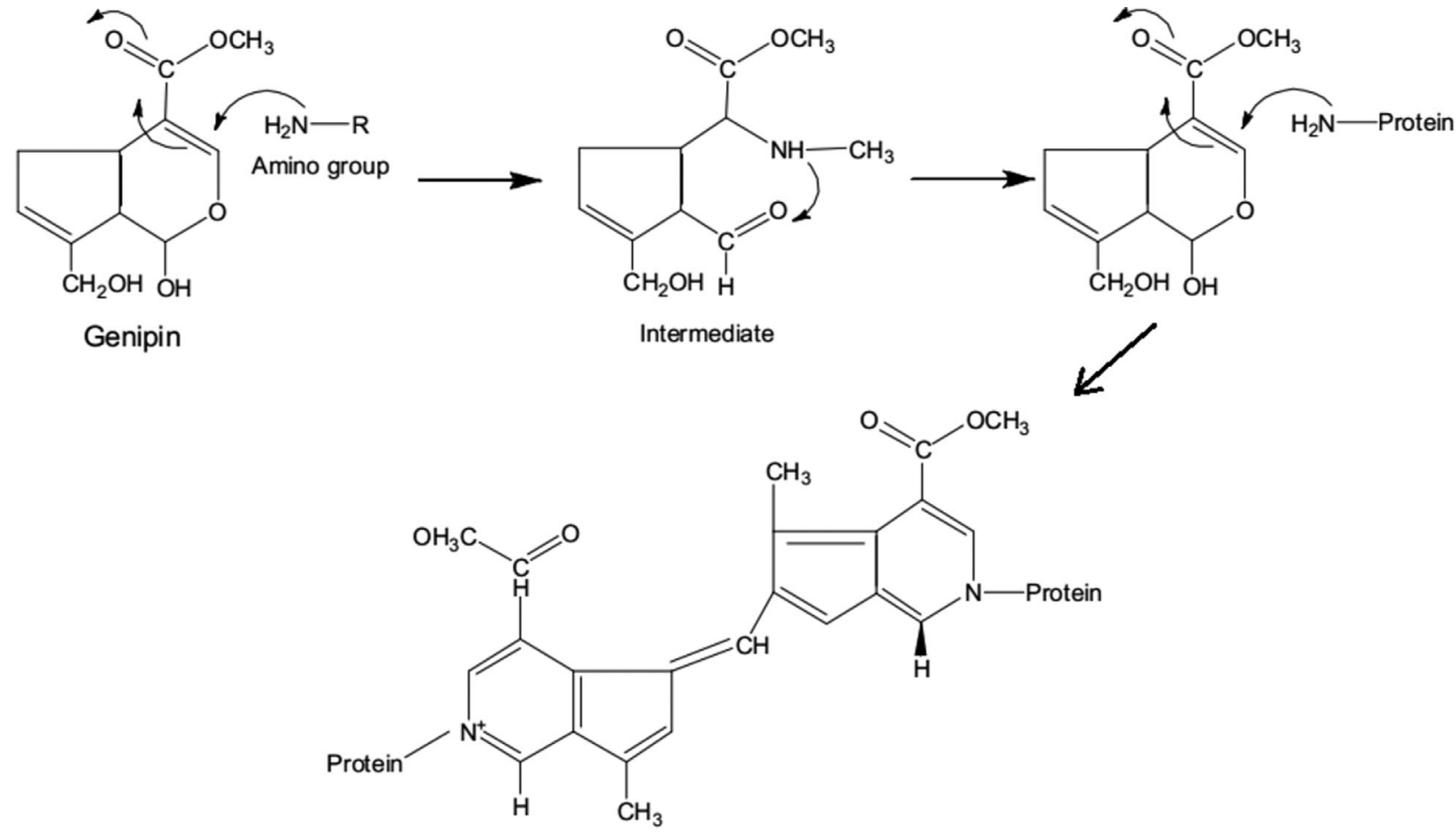

Figure 8. Cross-linking reaction of genipin with biopolymers containing free amine groups.

In addition to Tyr, direct modifications of particular amino acids, constituting silk fibroin chain, are possible. As such, chemically mediated Arg masking and enzymatically mediated Ser phosphorylation and Tyr oxidation are known. Arg masking is the positive charge screening of this amino acid by modification of its side chain with 1 , 2-cyclohexandione under basic conditions. The stability of the formed imidazolidinone reactant, bearing negative charge, depends on reaction conditions. ${ }^{[151,152]}$ The latter option, however, does not receive much attention possibly due to the low amounts of Arg present in silk. Enzymatically mediated reactions are discussed in the next chapter. Moreover, Tyr sulfonation can be performed by various ways. Gas plasma treatment, mentioned above, offers one possibility. Another method is to use chlorosulfonic acid in pyridine solution $^{[153]}$ (Figure 9). Sulfonation aims to impart anti-coagulant and anti-thrombogenic activity of SFderived materials; the second treatment resulted in the modification of both Tyr and Ser side chains. Developments of the second method were lately reported. Electrospun sulfated SF nanofibrous materials and PLGA scaffolds with covalently immobilized sulfated silk for vascular tissue engineering purposes have been fabricated. ${ }^{[154,155]}$ Recent work explored the feasibility of direct silk sulfonation, dissolved in the 1-butyl-3-methylimidazolium chloride ([BMIM]Cl, an ionic liquid). ${ }^{[156]}$ Milder reaction conditions and hence lower silk degradation were found to be the main benefits of the presented protocol.

The last possible working direction to be mentioned in this part is a sonochemical approach, i.e., ultra-soundassisted fabrication of nano- or micro-particles (spheres) from SF. In sonochemistry, the reacting molecules undergo a chemical transformation owing to the utilization of powerful ultrasound radiation $(20 \mathrm{kHz}-10 \mathrm{MHz}){ }^{[157]}$ It was postulated that no direct interaction at molecular level between the ultrasound and chemical species exists. Yet, chemical effects of ultrasound are exerted by an acoustic cavitation, in turn driven by high-intensity ultrasound. ${ }^{[158]}$ Ultrasonic irradiation of aqueous solutions generates highly reactive species like hydrogen $(\mathrm{H} \bullet)$ and hydroxyl $(\bullet \mathrm{OH})$

Figure 9. Proposed
chlorosulfonic acid. 
radicals. ${ }^{[159]}$ In the case of presence of oxygen, hydroperoxyl radicals $\left(\mathrm{HO}_{2} \bullet\right)$ can also be generated. These highly reactive intermediate products are used in different sonochemical reactions. SF-derived particles, produced by ultrasonic emulsification, possess high stability, low toxicity, and are found compatible as "drug carriers." Their sizes range in the interval between $500 \mathrm{~nm}-1.5 \mu \mathrm{m}$, what ascribes them to both nano- and micro-scale of the produced structures. ${ }^{[160]}$ Currently, there is a modest number of examples for the silk-derived materials, formulated by ultrasonication. Our group reported on both bovine serum albumin (BSA) and SF-based microspheres, formed by high-intensity ultrasound. ${ }^{[161]}$ BSA secondary structure was not disturbed during the microsphere synthesis, but an increase in the $\beta$-sheet content for silk was detected. A patent describing particular conditions for silk microspheres production was published. ${ }^{[162]}$ Recently, SF-based hydrogels, acquired by sonication, were used to deliver the therapeutic Bevacizumab, achieving sustained release for an in vivo animal system. ${ }^{[163]}$ An interesting system of nano- and microfibers production by sonication-controlled hydrolysis of raw-degummed fibroin was recently presented. ${ }^{[164]}$ The acquired degradation products had an MW of less than $20 \mathrm{kDa}$ in general and possessed alternated surficial and structural properties, comparing to the starting material. In some cases, sonication is used for the purposes of dispersion of already formed microspheres from the bulk phase. ${ }^{[109,165,166]}$ Much bigger spheres (up to $\approx 440 \mu \mathrm{m}$ ) can be produced by laminar jet break-up of aqueous SF solutions, induced by a nozzle, vibrating at a controlled frequency and amplitude. ${ }^{[167]}$ Moreover, sonication facilitates the phase separation of silk/poly-vinyl alcohol (PVA) blends to generate stable microspheres. ${ }^{[168]}$ Stability increased with augmentation of sonication amplitude and it correlated with increased $\beta$-sheet structures formation in SF. In the two latter cases, however, no sonochemistry per se is involved. A handy protocol compendium, describing various production methods of silk-based devices, including microspheres, is available. ${ }^{[26]}$

\subsection{Biochemical Approaches}

Biochemical (i.e., enzymatic) approaches will be the final part of the current review. In the last decades, numerous attempts were made to substitute the "conventional," purely chemical methods, by a more environment-friendly, the so-called "green chemistry" techniques. In that extent, enzymatically driven reactions attract significant attention, not only for being relatively non-hazardous or harsh treatments, but also due to their high specificity toward the substrates. The latter, however, is the source of their relatively low reaction yields, when compared to regular chemistry procedures. Moreover, as any proteinaceous molecule, the enzymes typically suffer from stability issues, what limits their application. We now shall focus on the reported examples of enzymatic treatments of fibrous materials.

Enzymatic treatments of SF commonly pursue two goals: its (selective) degradation or its conjugation with other polymers. Some chemical and mechanical properties of silk can be adjusted toward specific needs by the targeted degradation. For instance, $\beta$-sheet content of cast SF films, tuned by protease XIV and $\alpha$-chymotrypsin, demonstrated suitability of the method for the construction of temporary corneal stroma tissue for corneal tissue regeneration. ${ }^{[169]} \mathrm{SF}$ yarns, treated with the same enzymes, made it possible to establish the in vitro degradation model system, important for the mechanical and structural studies of fibrous materials. ${ }^{[170]}$ Another study, aiming similar purpose, was conducted on a spongy, porous SF sheets, partially cleaved by protease XIV, $\alpha$-chymotrypsin, and collagenase IA. $^{[171]}$ It has also been established that protease XIV was the most effective, against specific material type, while $\alpha$ - chymotrypsin was the least effective. SF powders, pre-treated with proteinase $\mathrm{K}$, demonstrated a porous network structure, when formed by a co-precipitation method with hydroxy-apatite solution. ${ }^{[172]}$ Moreover, some important implications of the treatment, like overall structure 3D crystallization growth, were detected. Selective and usually milder degradation of SF-based materials can be used for their further diversification. As such, proteolytic cleavage of the amorphous regions in SF solution by $\alpha$ - chymotrypsin leads to phase separation. Self-assembly of remaining regions into silk microgels was reported; the gels possessed a negative charge, were highly crystalline, and porous. ${ }^{[173]}$ For those microgels, the cationic drugs delivery system may be proposed. A comprehensive analysis on $\mathrm{SF}$ degradation rates and degradation-related products, originating from different cleavage pathways, was presented. Biocompatibility related issues that are the function of degradation type ("natural" or "unnatural") were observed and discussed. ${ }^{[174]}$ Efficient degradation of fibroin by a thermophile $B$. thermoruber ${ }^{[175]}$ and a comparison between acidmediated and various proteolytic enzymes hydrolyses of fibroin were reported. ${ }^{[176]}$ Additional cases of SF enzymemediated degradation were reviewed. ${ }^{[20]}$ An interesting study of sterilization means impact on enzymatic degradation and mechanical properties of silk-derived porous scaffolds was conducted. Structural rearrangements, resulting from autoclaving, affected the degradation and mechanical properties, but not ethanol sterilization that caused mild crystalline structure alterations. ${ }^{[177]}$

Enzymatic grafting of biomolecules like chitosan and lactoferrin was reported. Several works describe the conjugation techniques of chitosan, ${ }^{[178-181]}$ whilst only one recent study talks about bovine lactoferrin graft. ${ }^{[182]}$ In the first case, a mushroom tyrosinase (MT) is utilized to

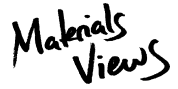

www.MaterialsViews.com
Macromol. Mater. Eng. 2015, 12, 1199-1216

(c) 2015 WILEY-VCH Verlag GmbH \& Co. KGaA, Weinheim 


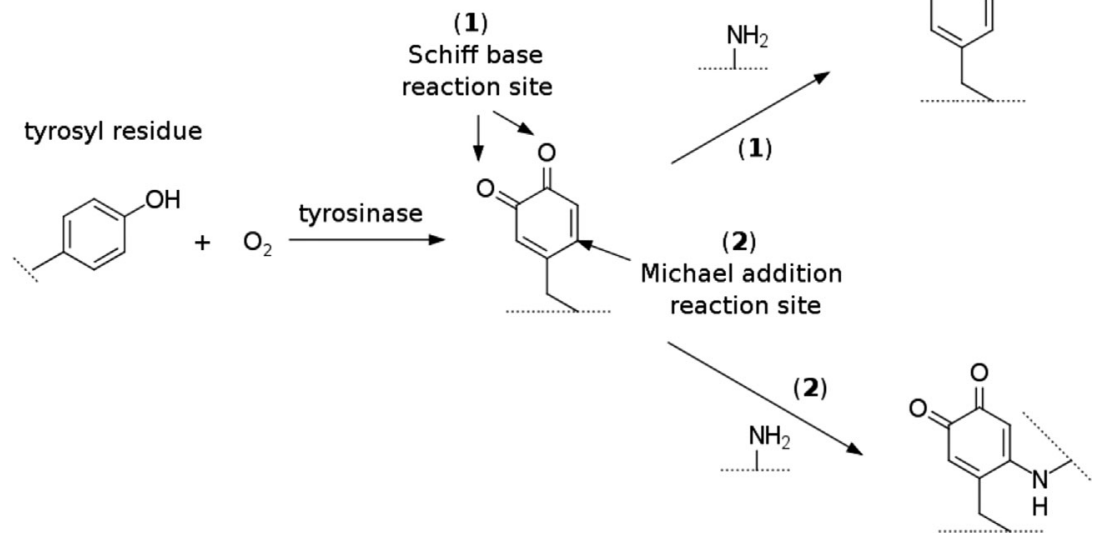

Figure 10. Selective oxidation of SF by MT enzyme and the subsequent grafting of chitosan onto oxidized silk. Figure adapted from ref. ${ }^{[181]}$

oxidize Tyr residues to electrophilic o-quinones. The formation of $o$-quinones is a determining step in the overall grafting reaction. Moreover, accessible tyrosyl groups that can be oxidized by MT, belong to the more solvent-accessible segments of SF chain; steric hindrance factors should be taken into consideration. Subsequently, 0 quinones react non-enzymatically with nucleophilic amino groups of chitosan by Schiff-base and Michael addition mechanisms (Figure 10). Chitosan grafting provokes considerable changes in the thermal behavior of SF, caused by $\beta$-sheet $\rightarrow$ random coil conformational transition. Due to the hardness of the conjugated materials, they may be utilized in the applications of elevated stiffness such as scaffolds. For lactoferrin grafting, silk fabrics are also treated with MT and the protein of interest is later added. Lactoferrin is an iron chelater, what contributes to its bacteriostatic ability. Furthermore, lactoferrin can interact with the bacterial cell membrane and make it lose its barrier function. In the reported work, lactoferrin-enhanced silk fabrics showed "encouraging" bacteriostatic activity against the gram-positive and -negative bacterial species.

Additional approaches to functionalize silk are comprised of two more strategies of preparing fibrous polymeric structures (hydrogels and segmented block copolymers), enzymatically driven mineralization of silk scaffolds, and in vitro phosphorylation of SF. Horseradish peroxidase (HRP)/hydrogen peroxide system was presented as a mean of fabricating SF hydrogels with tuneable $\beta$-sheet content. Gels, initially elaborated with random-coiled structure (silk I or amorphous) converted to $\beta$-stacks after prolonged (7 d or more) exposition to the surroundings. Attempt of human malignant cell lines (HeLa, U251) cultivation was made; a growth inhibition of both lines was detected. ${ }^{[183]}$

A series of data regarding poly(acrylonitrile-co-SF peptide) syntheses was previously divulgated. The common strategy was to co-polymerize acrylonitrile (AN) with a vinyl-decorated SF peptide (Figure 11). The peptides were acquired by enzymatic digestion of SF powder by $\alpha$ - chymotrypsin and subsequently reacted with acryloyl chloride in appropriate solution. To obtain the final products, polymerization with AN was carried out. One article described various possible AN-containing formulations, obtained by random copolymerization, graft-polymerization, and blended material type ${ }^{[184]}$ In the next paper, segmented block co-polymer was enhanced during the course of its synthesis by zinc ions, between the acylation phase with acryloyl chloride and the final AN co-polymerization. The obtained materials exhibited good odor-removing and antibacterial properties. ${ }^{[185]}$ The last work combined all aforementioned methods with a wet-spinning process, thus fabricating poly(acrylonitrile-co-SF peptide) fibers. ${ }^{[186]}$

Alkaline phosphatase (ALP)-assisted in situ mineralization of pre-fabricated SF-based porous scaffolds was reported. Electrostatic attractions between ALP and SF scaffolds anchor the enzyme. Later, provided with mineralization medium (mixture of glycerol phosphate calcium salt and calcium phosphate salts), deposition of mineral calcium phosphate was observed ${ }^{[187]}$ (Figure 12). Researches also elucidated the relationship between mineralization degrees and osteoblast cell line responses that was inversely correlated. In this particular case, although the fibroin was not modified directly by the enzyme, the mineralization would not be possible without ALP.

Lastly, in vitro enzymatic phosphorylation of specific amino acid, Ser was reported. Since the pioneering work of Winkler et al., ${ }^{[188]}$ it was further developed by our group. Winkler and co-workers successfully phosphorylated genetically engineered spider silk with protein kinase A

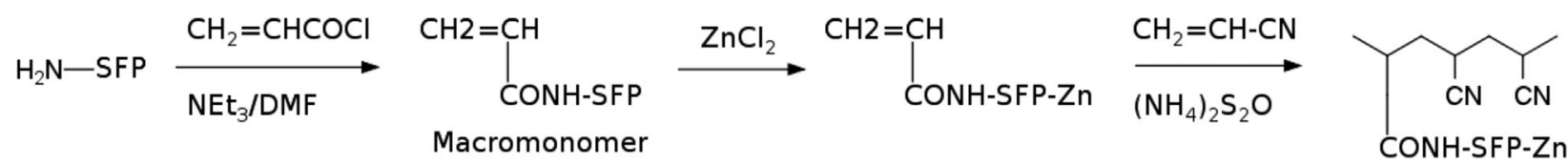

Figure 11. Example of synthesis procedure of Zn (II)-poly(acrylonitrile-co-SF) complex. Figure taken from ref. ${ }^{[185]}$ 


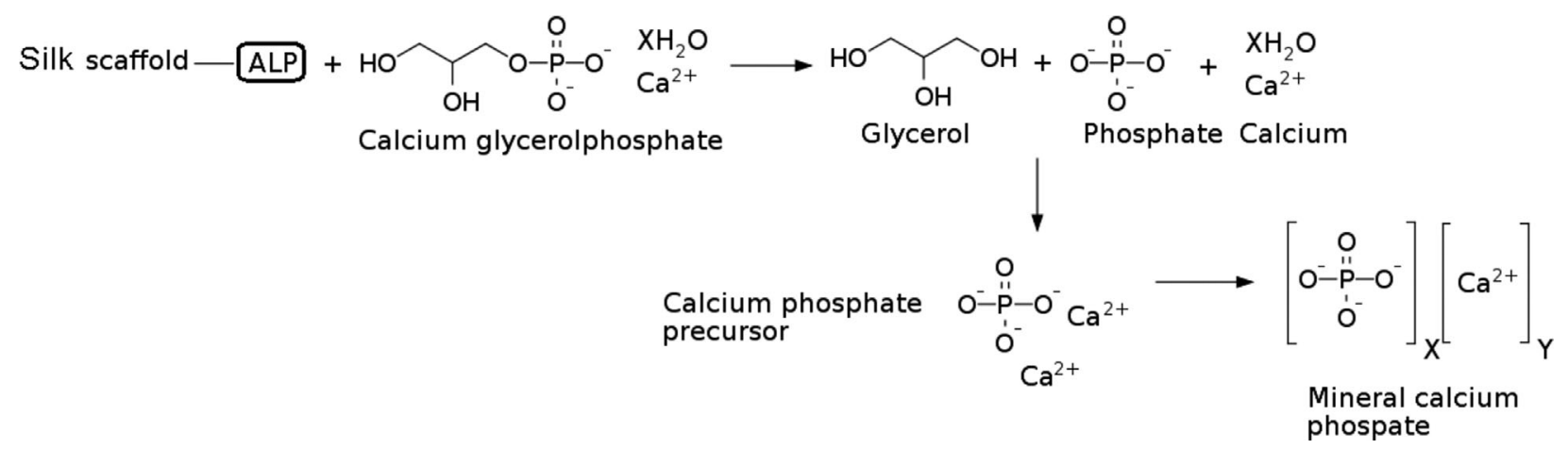

Figure 12. Proposed reaction mechanism of ALP with calcium phosphate. Figure taken from ref. ${ }^{[187]}$

(PKA), presenting the possibility to enzymatically modify fibrous materials in a particular way. Our findings on processing the wild-type mulberry silk demonstrate the following ${ }^{[189,190]}$ : (a) this silk, when appropriately dissolved, can undergo in vitro enzymatic phosphorylation; and (b) phosphorylation allows to tune various chemical and physical properties of silk, what can be used for specific applications. Although the phosphorylation levels were quite low (Figure 13), those impose strong effects on structural conformation of SF (lesser $\beta$-sheet content) and increased hydrophilicity, accompanied by augmentation of negative charges at physiological $\mathrm{pH}$. In that context, it is worth noticing that the outcomes of cell culturing $[183,189,191-193]$ indicate that conformation transition within silk, as well as surface properties, are responsible for cellular attachment/proliferation. Thus, if a silk as biomaterial of choice is used and treated by the "green" method, its properties can be tuned and the issues of biocompatibility can be avoided or considerably alleviated.

\section{Formulated Products From Processed RSF}

Until now, our description was mainly concentrated on the means of RSF diversification, without special accent given to processing/formulation aspects. Different final formulations (films, scaffolds, hydrogels, etc.), although mentioned, had a subordinate importance. Notwithstanding, it is no less important to state those processing options leading to a final product form. Figure 14 summarizes the following chapter.

Films (or mats) of varying mechanical and structural properties can be obtained by solvent casting of RSF solutions. At solvent evaporation phase by controlling environment conditions, such as temperature, $\mathrm{pH}$, and the physical amounts of the poured solution, final stiffness may be tailored. ${ }^{[190,194]}$ Desired surface topography is determined by the used molds of a pre-designed form; ${ }^{[194]}$ moreover, enhancing stress and strain is performed by the stretching of a dried material. ${ }^{[195]}$ The composition of source RSF solution may influence the fine structure of elaborated films, for instance, SF films cast from formic acid appear to be more crystalline than their water-derived counterparts. ${ }^{[77]}$ On the contrary, decreased $\beta$-sheet content coupled to water insolubility was achieved by decreasing the drying rate of RSF solution. ${ }^{[196]}$ A development of the latter method was published, where films, prepared by slow drying process, were rehydrated and subsequently stretched. ${ }^{[197]}$ The increased content of bound water was thought to impose a plasticization effect, resulting in more flexible and prone to degradation product, yet waterinsoluble.

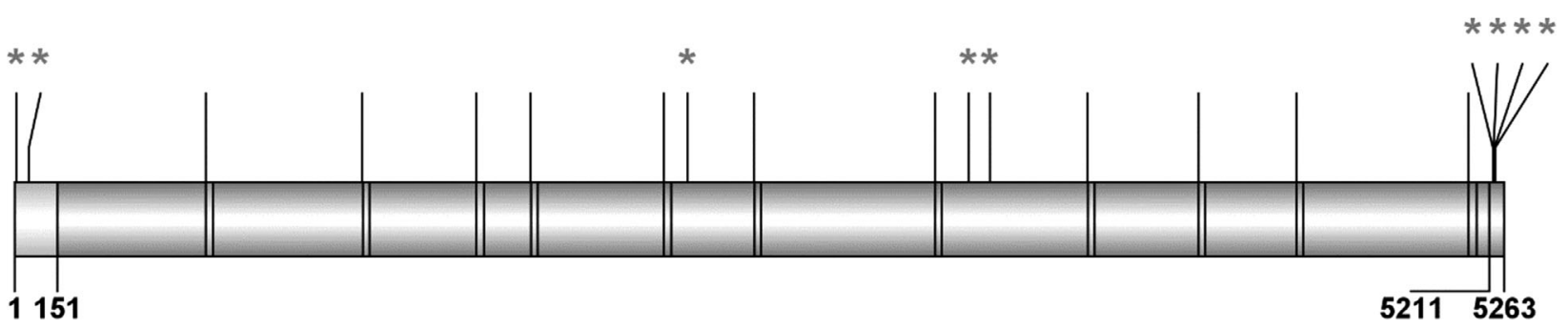

Figure 13. The representation of predicted phospho-sites in silk fibroin. The sites, resulting from different prediction methods (asterisks, predicted in silico, others by sequence analysis of protein kinase A consensus motif), are indicated by thin lines. The major segment types, present in the protein, are depicted. Those include the $\mathrm{N}$-terminal acidic and $\mathrm{C}$-terminal basic domains and 11 "amorphous" sequences (shown as thick lines). Figure adapted and reproduced with permission from 2015 WILEY-VCH Verlag GmbH \& Co. ${ }^{[189]}$

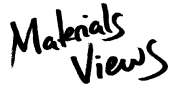

www.MaterialsViews.com
Macromol. Mater. Eng. 2015, 12, 1199-1216

(c) 2015 WILEY-VCH Verlag GmbH \& Co. KGaA, Weinheim 


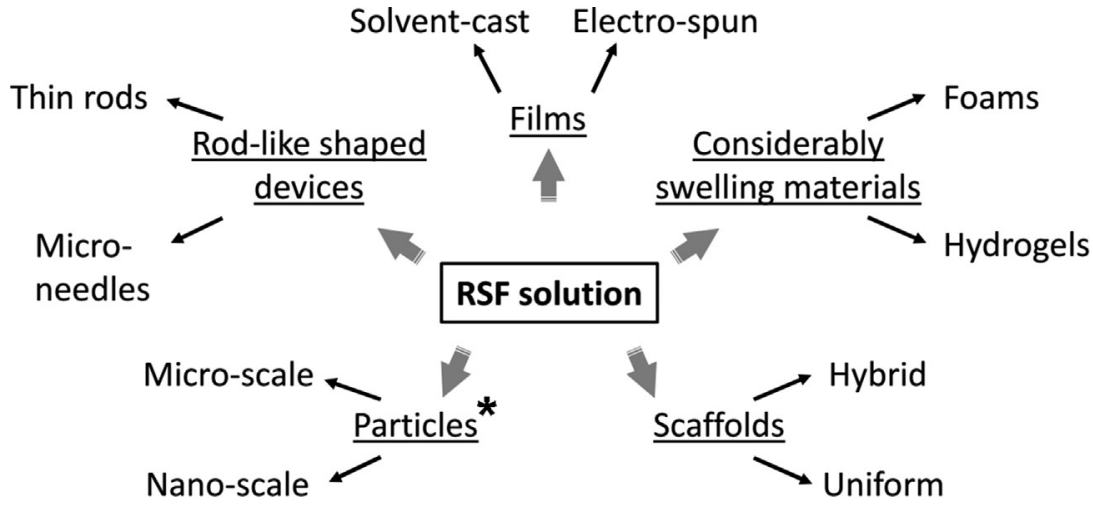

Figure 14. A variety of silk-based materials, formulated from RSF. Note: SF particles could also be acquired from the raw-degummed fiber, and not only from the regenerated silk solution.

Another way of producing silk mats and nanofibers is electrospinning. Activated, i.e., previously dissolved silk (typically stored in dry form) is re-dissolved in FA or HFIP-containing solutions and supplied to the electrospinning system. ${ }^{[74,198,199]}$ By changing starter solution (protein concentration content, helper chemicals, and other blended compounds of interest), different aspects of the finally produced materials are governed. ${ }^{[74,199]}$

Hydrogels, that may be used for mimicking the aquatic environment in vivo, are obtained from RSF aqueous solutions. The naturally present tendency of solvated silk molecules for hydrophobic self-aggregation ${ }^{[200]}$ is exploited in several methods, that include, but not limited to, the elaboration of composite SF and nanohydroxyapatite (HA) gels, ${ }^{[201]}$ hydrogels and lyogels, ${ }^{[202]}$ nanofiber hydrogels, ${ }^{[203]}$ reinforced hyaluronan-silk hydrogels. ${ }^{[204]}$ In the listed examples, EtOH, sonication and subsequent lyophilization and slow concentrationdilution process were used as gelling agents. The last method, however, included SF electrospinning as mean of hard support production, on which the hyaluronanbased gel was later mounted. All of the above materials demonstrated biocompatibility ${ }^{[201,203]}$ or controlled release of the incorporated therapeutic molecules. ${ }^{[202,204]}$ Further developments of RSF gelation via dehydration by dialysis against $\mathrm{MeOH}$ or via nanofiber preliminary formation in regenerated aqueous silk solution were reported. ${ }^{[205,206]}$ Interestingly, in the last work sonication was used to transfer the prepared hydrogel to solution. Silk nanofibers, formed by a slow concentration-dilution process of silk solution, ruptured under ultrasonic treatment, thus making hydrogel-solution transition possible.

Foams for regenerative or supporting medicine applications were reported. Those foams were injectable and obtained either by freezer-processing ${ }^{[207]}$ or polyethylene glycol (PEG)-based gelation ${ }^{[208]}$ techniques. The first method is actually a lyophilization process, preceded by mild freezing that determines the fine structural and hydrophilic features of the formed device. The second approach relies on dehydration of a fibroin in the presence of more hydrophilic PEG polymer. Lyophilizationobtained foams were utilized, among other, in filling soft tissue defects in a rat model, while PEG-containing foams were examined for an alternative to cervical cerclage therapy.

Rods (or microtubes) and microneedles (MNs) of several diameters and shapes can be fabricated for different purposes. As such, formulated silk microtubes, either porous or continuous for a microvascular replacement applications ${ }^{[209]}$ and reservoir rods for long-term sustained drug delivery ${ }^{[210]}$ are known. Rods and microtubes were done by dipping steel wire into SF solution with subsequent $\mathrm{MeOH}$ application, or by injection of silk feeder solution through a narrow gauge needle onto a steel wire following heat treatment, respectively. The latter method is termed "film-spinning." Both $\mathrm{MeOH}$ and heating treatments aimed to induce material crystallinity and confer resistance to the contact with aqueous environment. The porosity of the microtubes was controlled by blending ratios of SF/PEO, following the extraction of PEO in water. Increased concentrations of SF produced microtubes with the lowest pore sizes, while the opposite was observed when increased concentrations of PEO were used in the blends.

Some works describe the production of patterned MNs for drug delivery applications. In one case, silk/polyacrylic acid (PAA) pyramidal composite arrays of MNs, bearing encapsulated compound in either PAA pedestals, or silk tips, were made. A rapid initial release was detected from PAA base part of the MN, yet the silk cone showed slow/ sustained release over time. ${ }^{[211]}$ Another example constitutes slender, normal, and bullet type MNs, whose forms were dictated by the casting mold geometry. The mechanical properties of $\mathrm{MNs}$ were enhanced by $\mathrm{MeOH}$ application and bullet shaping. ${ }^{[212]}$ Finally, the silk-based MN patches of varying dimensions, tip diameter, base, and cone angle of the individual needles have been prepared. The mechanical properties of the MNs can be adjusted by post-fabrication vapor-annealing or by loading the needles with silk microparticles. The microparticles, in turn, were prepared with silk and PVA using a phase separation method. [213]

Particles of different sizes and shapes can either be produced by milling, emulsification, laminar jet break-up, or sonication. If milling is used, degummed SF is chopped, the chopped snippets are then wet milled and the obtained silk slurry is spray-dried to recover the silk powder. ${ }^{[214]}$ 
Deviations from the stated method exist, resulting in particles with different properties. For instance, milling may reduce intermolecular $\beta$-sheet stacking and cause some decrease in MW of fibroin without changing the intramolecular binding energy. Rough morphology and the ultrafine particle size result in the increased enzymatic degradation, as compared to raw fibers. ${ }^{[215]}$ Particles obtained by attritor-bead mill combination with alkaline charge repulsion and surfactant repulsion methods possessed an evidence of amorphous content reduction, increase in surface area, and also reduction in crystallinity. ${ }^{[216]}$ Alternatively, particles can be formulated using an emulsion method with PVA as emulsifier. Here, an intermediate step, involving SF/PVA film production and SF particles acquisition by PVA extraction, was taken. ${ }^{[217]}$ Laminar jet break-up and sonication approaches were previously discussed in the last paragraph of Section 3.1.

Scaffolds, whether planar or 3D, are fabricated throughout several methods, of which the most common ones are freeze-drying and salt-leaching. Only few examples among many are currently presented. Some works report on electrospinning for hydrophilic and biodegradable planar devices of SF/PLGA ${ }^{[218]}$ or hybrid salt-leached porous scaffolds on solid film support. ${ }^{[219]}$ An interesting improvement of the lyophilization-based method was recently presented in a group of works. ${ }^{[80,220,221]}$ Prior to lyophilization, RSF solutions are let to slowly self-assemble in aqueous media without any additional cross-linkers or (potentially toxic) solvents. In some cases, a repeated drying-dissolving process is invoked, where a series of casting, drying, and re-dissolution of SF material is made, followed by a final freeze-drying step. ${ }^{[220]}$ The fibroin rearrangements during the liquid phases, preceding final formulation, result in a more soluble silk nanofiber formation without dense, hydrophobic silk II transition. The latter fact has a positive impact on biocompatibility, mechanical properties (softness), and improved cell growth and differentiation behavior. Later treatments of the lyophilized materials, such as gradient water/MeOH annealing, may be used to control additional secondary structures, mechanical properties, and degradation of the scaffolds. Yet, another way to decrease the unwanted SF conformation transition from random coil to $\beta$-sheet stacking can be achieved by blending hyaluronan with silk. ${ }^{[22]}$ All of the above approaches improve SF applicability in tissue engineering applications.

\section{Conclusion}

Of the various steps in fibroin processing, several do have a "multiple-choice" option of achieving the desired goal. Let us briefly state the most plausible options for some key stages of the processing
A primary degumming step of raw material is commonly done by boiling in alkaline media (Section 2.1). The process demonstrates good yields and repeatability, however, it partially damages (degrades) the fibroin that can be unwanted. For that, using a cocoonase with no effect on a fiber looks a more promising method.

SF dissolution routine type is dictated by the subsequent step(s) in the workflow, so that no specific preference for any of the enumerated methods can be outlined (Section 2.3). For aqueous SF solutions, near-saturated bromides and or thiocyanates are typically used. The main drawback of aqueous solutions is that they need to be dialyzed, and after the salt removal such solutions are unstable, rendering long-term storage of the material very hard. Silk concentration and/or storage temperature of the aqueous solution play pivotal roles in silk stability within that solution.

Lyophilization or freeze-drying is by all means an important step in SF processing chain. Being a purely physical phenomenon, it can be used in a final step of silk "activation" prior to its re-dissolution, or serve a final goal per se, as a method of formulation (Section 2.4). Other techniques of similar type, commonly employed for their simplicity, are LBL deposition, solvent casting, and gelation (Sections 2.4-2.5). Gelation and crystallinity induction are mechanistically close phenomena, and can both be controlled by same factors of temperature, shear stress, or additives introduced to SF while still being in a liquid phase. Since gelation outcomes (morphology, crystallinity degree, mechanical properties) are controlled by many factors, it is up to the researcher to choose the most appropriate method. For instance, $\mathrm{Ca}^{2+}$ comparing to $\mathrm{K}^{+}$at the same concentrations induces a slower gelation, poloxamer-blended SF of the same concentration gelated much faster than its PEG-blended counterpart. Invariantly, the gelation was facilitated by increasing SF content and/or ambient temperature. For the maximal crystallinity induction, soaking in methanol is probably one of the best ways, yet it results in hazardous methanol waste.

Coupling processes, based on carbodiimide-derived chemistry, constitute the most significant part of the literature describing SF enhancement by grafting. It is a well-established method with the known advantages and pitfalls. The more recent "click chemistry" approach seems to be free of safety concerns that substantially challenge carbodiimide-based reactions (Section 3.1); however, it is more costly.

Sonochemistry is another completely different, but valuable tool in SF-based product formulation and entrapping the compounds of interest within silk (Section 3.1) for their further controlled delivery. Unfortunately, this method exerts harsh preparation conditions that could be detrimental to sensitive molecules intended for incorporation.

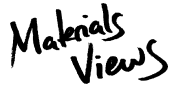

www.MaterialsViews.com
Macromol. Mater. Eng. 2015, 12, 1199-1216

(C) 2015 WILEY-VCH Verlag GmbH \& Co. KGaA, Weinheim 
High temperatures and shear stresses elicit denaturing conditions for protein therapeutics. Therefore, when the desired compound possesses known liability, laminar jet break-up, water-in-oil emulsion solvent diffusion, desolvation/coacervation, or other mild-conditioned methods are preferable (some are reviewed in ref. ${ }^{[223]}$ ).

Enzymatic approaches constitute a separate Section 3.2. From variety of the listed possibilities, of processing significance are the enzymes for (selective) degradation and grafting. In the first case, controlled degradation may be used for fine tuning of the formed structure in a treated material, or for recycling sericultural wastes. In the second case, enzymatic grafting of molecules via modified Tyr residue is worth noticing, due to its even distribution within SF heavy chain sequence.

The current review presented the hallmark of the major processing options of SF for the laboratory scale. It stands to reason that different routines can be successfully combined to pursue particular research goals. It seems that traditional chemical approaches still dominate over the "green chemistry;" however, the significant direction toward environmentally friendly methods has been constantly developing. "Green chemistry" reagents along with natural catalysts (enzymes) started to gain wider acknowledgement in the last decades. Despite the fact that overwhelming amount of the enzymes is still far from being as available and effective as traditional chemical techniques, further improvements of their properties (stability, diversified consensus sequences, availability) will aid in solving the aforementioned issues in the future.

$\begin{array}{ll}\text { Abbreviations } \\ {[\mathrm{BMIM}] \mathrm{Cl}} & \text { butyl-3-methylimidazolium chloride } \\ \bullet^{\circ H} & \text { hydroxyl radical } \\ \mathrm{ALP} & \text { Alkaline phosphatase } \\ \mathrm{AN} & \text { acrylonitrile } \\ \text { B. mori } & \text { Bombyx mori } \\ \mathrm{BmCoc} & \text { B. mori cocoonase } \\ \mathrm{BSA} & \text { bovine serum albumin } \\ \mathrm{Ca}\left(\mathrm{NO}_{3}\right)_{2} & \text { calcium nitrate } \\ \mathrm{CaCl} & \\ \mathrm{CuAAC} & \text { calcium chloride } \\ \mathrm{Cuoxam} & \text { copper I-catalyzed azide-alkyne cycloaddition } \\ \text { EDC } & \text { 1-ethyl-3-dimethylaminopropyl carbodiimide } \\ \text { EHD } & \text { electrohydrodynamic bubbling } \\ \text { EO } & \text { ethylene oxide } \\ \text { ESR } & \text { electron spin resonance } \\ \text { EtOH } & \text { ethanol } \\ \text { FA } & \text { formic acid } \\ \text { FBS } & \text { foetal bovine serum } \\ \text { FDA } & \text { Food and Drug Administration } \\ \mathrm{H} \bullet & \text { hydrogen radical } \\ \mathrm{HA} & \text { hydroxyapatite }\end{array}$

\begin{tabular}{|c|c|}
\hline HFA & hexafluoro-acetone \\
\hline HFIP & hexafluoro-2-propanol \\
\hline $\mathrm{HO}_{2}{ }^{\bullet}$ & hydroperoxyl radical \\
\hline HRP & Horseradish peroxidase \\
\hline LBL & layer-by-layer \\
\hline $\mathrm{LiBr}$ & lithium bromide \\
\hline LiSCN & lithium thiocyanate \\
\hline $\mathrm{MeOH}$ & methanol \\
\hline MMNO & $N$-methyl morpholine $N$-oxide hydrate \\
\hline $\mathrm{MN}$ & microneedle \\
\hline MOI & 2-Methacryloyloxyethyl isocyanate \\
\hline MPC & 2-methacryloyloxyethyl phosphorylcholine \\
\hline MT & mushroom tyrosinase \\
\hline MW & molecular weight \\
\hline $\mathrm{Na}_{2} \mathrm{CO}_{3}$ & sodium carbonate \\
\hline $\mathrm{NaSCN}$ & sodium thiocyanate \\
\hline $\mathrm{NH}_{3}$ & ammonia \\
\hline NHS & $N$-hydroxysuccinimide \\
\hline PAA & polyacrylic acid \\
\hline PEG & polyethylene glycol \\
\hline PEO & polyethylene oxide \\
\hline PKA & protein kinase $\mathrm{A}$ \\
\hline PLGA & poly lactic-co-glycolic acid \\
\hline PVA & poly-vinyl alcohol \\
\hline RSF & regenerated silk fibroin \\
\hline $\mathrm{SaOS}-2$ & sarcoma osteogenic cell line \\
\hline SDS & sodium dodecyl sulfate \\
\hline $\mathrm{SF}$ & silk fibroin \\
\hline $\mathrm{SO}_{2}$ & sulfur dioxide \\
\hline UV & ultraviolet \\
\hline VEGF & vascular endothelial growth factor \\
\hline
\end{tabular}

Acknowledgement: V. V. wants to thank Nuno Azoia for the schemes of chemical reactions.

Received: May 13, 2015; Revised: June 18, 2015; Published online: August 27, 2015; DOI: 10.1002/mame.201500179

Keywords: biomaterials; improved properties; modification; silk fibroin

[1] F. Wang, H. Xu, Y. Wang, R. Wang, L. Yuan, H. Ding, C. Song, S. Ma, Z. Peng, Z. Peng, P. Zhao, O. Xia, Acta Biomater. 2014, 10, 4947

[2] D. Naskar, S. Nayak, T. Dey, S. C. Kundu, Sci. Rep. 2014, 4, 4745.

[3] H. Yang, M. Sun, P. Zhou, L. Pan, C. Wu, J. Biomed. Sci. Eng. 2010, 3, 1146.

[4] K. Tsioris, H. Tao, M. Liu, J. A. Hopwood, D. L. Kaplan, R. D. Averitt, F. G. Omenetto, Adv. Mater. 2011, 23, 2015.

[5] H. Tao, M. A. Brenckle, M. Yang, J. Zhang, M. Liu, S. M. Siebert, R. D. Averitt, M. S. Mannoor, M. C. McAlpine, J. A. Rogers, D. L. Kaplan, F. G. Omenetto, Adv. Mater. 2012, 24, 1067. 
[6] D. Naskar, R. R. Barua, A. K. Ghosh, S. C. Kundu, in "Silk Biomaterials for Tissue Engineering and Regenerative Medicine", 1st edition, S. Kundu, Ed., Woodhead Publishing Limited, Sawston, Cambridge 2014, p. 23.

[7] A. Leal-Egana, T. Scheibel, Biotechnol. Appl. Biochem. 2010, 55, 155.

[8] D. Kaplan, in "Silk: Biology, Structure, Properties, and Genetics in Silk Polymers", D. A. Kaplan, W. Wade, F. Barry, V. Christopher, Eds., American Chemical Society, Charlottesville, Virginia 1994, p. 2.

[9] S. Anna, C. Camilla, B. Valentina, D. V. Nicola, T. Stefano, C. Susanna, P. Tamara, P. Assunta, V. Greta, R. Giampiero, M. Michele, R. Federica, Z. Roberto, Compos. Part B 2015, 68, 281

[10] H. Wen, X. Lan, Y. Zhang, T. Zhao, Y. Wang, Z. Kajiura, M. Nakagaki, Mol. Biol. Rep. 2010, 37, 1815.

[11] Z. Cao, X. Chen, J. Yao, L. Huang, Z. Shao, Soft Matter 2007, 3, 910.

[12] C. Vepari, D. L. Kaplan, Prog. Polym. Sci. 2007, 32, 991.

[13] S. Inoue, K. Tanaka, F. Arisaka, S. Kimura, K. Ohtomo, S. Mizuno, J. Biol. Chem. 2000, 275, 40517.

[14] C. Z. Zhou, F. Confalonieri, M. Jacquet, R. Perasso, Z. G. Li, J. Janin, Proteins 2001, 44, 119.

[15] X. Chen, Z. Shao, N. S. Marinkovic, L. M. Miller, P. Zhou, M. R. Chance, Biophys. Chem. 2001, 89, 25.

[16] A. Hyde, C. Wippler, J. Polym. Sci. 1962, 58, 1083.

[17] C. Z. Zhou, F. Confalonieri, N. Medina, Y. Zivanovic, C. Esnault, T. Yang, M. Jacquet, J. Janin, M. Duguet, R. Perasso, Z. G. Lim, Nucleic Acids Res. 2000, 28, 2413.

[18] Y. Yang, C. Dicko, C. D. Bain, Z. Gong, R. M. J. Jacobs, Z. Shao, A. E. Terry, F. Vollrath, Soft Matter 2012, 8, 9705.

[19] C. W. P. Foo, E. Bini, J. Hensman, D. P. Knight, R. V. Lewis, D. L. Kaplan, Appl. Phys. A 2006, 82, 223.

[20] Y. Cao, B. Wang, Int. J. Mol. Sci. 2009, 10, 1514.

[21] E. lizuka, J. Yang, Biochemistry 1968, 7, 2218.

[22] H. Takeuchi, T. Gomi, M. Shishido, H. Watanabe, N. Suenobu, J. Dermatol. Sci. 2010, 60, 151.

[23] R. Valluzzi, S. P. Gido, W. Muller, D. L. Kaplan, Int. J. Biol. Macromol. 1999, 24, 237.

[24] G. Li, H. Liu, T.-D. Li, J. Wang, Mater. Sci. Eng. C 2011, 32, 627.

[25] M. N. Padamwar, A. P. Pawar, J. Sci. Ind. Res. 2004, 63, 323.

[26] D. N. Rockwood, R. C. Preda, T. Yucel, X. Wang, M. L. Lovett, D. L. Kaplan, Nat. Protoc. 2011, 6, 1612.

[27] S. Unajak, S. Aroonluke, A. Promboon, J. Sci. Food Agric. 2014, 95, 1179.

[28] G. H. Altman, F. Diaz, C. Jakuba, T. Calabro, R. L. Horan, J. Chen, H. Lu, J. Richmond, D. L. Kaplan, Biomaterials 2003, 24 401.

[29] C. M. Wen, S. T. Ye, L. X. Zhou, Y. Yu, Ann. Allergy 1990, 65, 375.

[30] Y. O. Zhang, W. L. Zhou, W. D. Shen, Y. H. Chen, X. M. Zha, K. Shirai, K. Kiguchi, J. Biotechnol. 2005, 120, 315.

[31] T. T. Cao, Y. J. Wang, Y. O. Zhang, PLoS ONE 2013, 8, e65654.

[32] H.-Y. Wang, Y.-O. Zhang, Soft Matter 2013, 9, 138.

[33] O. Wang, O. Chen, Y. Yang, Z. Shao, Biomacromolecules 2013, 14, 285.

[34] L. S. Wray, X. Hu, J. Gallego, I. Georgakoudi, F. G. Omenetto, D. Schmidt, D. L. Kaplan, J. Biomed. Mater. Res. Part B, Appl. Biomater. 2011, 99, 89.

[35] S. Viju, G. Thilagavathi. J. Text I. 2012, 104, 289.

[36] E. Panas-Perez, C. J. Gatt, M. G. Dunn, J. Mater. Sci. Mater. Med. 2013, 24, 257.

[37] H. Fan, H. Liu, Y. Wang, S. L. Toh, J. C. Goh, Cell Trans. 2008, 17, 1389.

[38] S. Sahoo, S. L. Toh, J. C. Goh, Biomaterials 2010, 31, 2990.
[39] H. Z. Zhao, M. Li, Adv. Mat. Res. 2011, 175-176, 95.

[40] X. Li, J. G. Snedeker, J. Mech. Behav. Biomed. Mater. 2013, $22,30$.

[41] W. Shen, X. Chen, Y. Hu, Z. Yin, T. Zhu, J. Hu, J. Chen, Z. Zheng, W. Zhang, J. Ran, B. C. Heng, J. Ji, W. Chen, H. W. Ouyang, Biomaterials 2014, 35, 8154.

[42] M. Sakamoto, F. Masuko, S. Nakanishi, Text. Res. J. 1986, 56, 429.

[43] M. Sakamoto, Y. Kumeno, S. Deno, T. Yamauchi, M. Nishimoto, K.-I. Furuhata, F. Masuko, Text. Res. J. 1988, 58, 689.

[44] Y. H. Lu, H. Lin, Y. Y. Chen, C. Wang, Y. R. Hua, Fiber. Polym. 2007, 8, 1

[45] C. Solazzo, J. M. Dyer, S. Deb-Choudhury, S. Clerens, P. Wyeth, Photochem. Photobiol. 2012, 88, 1217.

[46] S. Periyasamy, D. Gupta, M. L. Gulrajani, Eur. Polym. J. 2007, 43, 4573.

[47] S. Periyasamy, D. Gupta, M. L. Gulrajani, J. Appl. Polym. Sci. 2007, 103, 4102.

[48] V. Mamedov Sh, B. Aktas, M. Canturk, B. Aksakal, V. Alekperov, F. Bulbul, R. Yilgin, R. B. Aslanov, Biomaterials 2002, 23, 3405.

[49] D. Sargunamani, N. Selvakumar, Polym. Degrad. Stabil. 2006, 91, 2644.

[50] M. F. Elahi, G. Guan, L. Wang, M. W. King, Materials 2014, 7, 2956.

[51] A. B. Mathur, A. Tonelli, T. Rathke, S. Hudson, Biopolymers 1996, 42, 61.

[52] X. Chen, D. P. Knight, Z. Shao, F. Vollrath, Polymer 2001, 42, 09969.

[53] F. Zhang, O. Lu, X. Yue, B. Zuo, M. Oin, F. Li, D. L. Kaplan, X. Zhang, Acta Biomater. 2015, 12, 139.

[54] N. Singh, S. S. Rahatekar, K. K. K. Koziol, T. Sky Ng, A. J. Patil, S. Mann, A. P. Hollander, W. Kafienah, Biomacromolecules 2013, 14, 1287.

[55] D. M. Phillips, L. F. Drummy, D. G. Conrady, D. M. Fox, R. R. Naik, M. O. Stone, P. C. Trulove, H. C. De Long, R. A. Mantz, J. Am. Chem. Soc. 2004, 126, 14350.

[56] N. Agarwal, D. A. Hoagland, R. J. Farris, J. Appl. Polym. Sci. 1997, 63, 401

[57] Y. Y. Sun, Z. Z. Shao, M. H. Ma, P. Hu, Y. S. Liu, T. Y. Yu, J. Appl. Polym. Sci. 1997, 65, 959.

[58] E. S. Sashina, A. M. Bochek, N. P. Novoselov, D. A. Kirichenko, Russ. J. Appl. Chem. 2006, 79, 869.

[59] G. Guang Yang, L. Zhang, Y. Liu, J. Membr. Sci. 2000, 117, 153.

[60] R. You, Y. Zhang, Y. Liu, G. Liu, M. Li, Nat. Sci. 2013, 5, 10.

[61] K. Matsumoto, H. Uejima, J. Polym. Sci., Part A 1997, 35, 1949.

[62] G. Freddi, G. Pessina, M. Tsukada, Int. J. Biol. Macromol. 1999, 24, 251.

[63] E. Wenk, H. P. Merkle, L. Meinel, J. Control. Release 2011, 150, 128.

[64] Y. Wang, H. J. Kim, G. Vunjak-Novakovic, D. L. Kaplan, Biomaterials 2006, 27, 6064 .

[65] E. M. Pritchard, P. B. Dennis, F. Omenetto, R. R. Naik, D. L. Kaplan, Biopolymers 2012, 97, 479.

[66] H. J. Kim, U. J. Kim, H. S. Kim, C. Li, M. Wada, G. G. Leisk, D. L. Kaplan, Bone 2008, 42, 1226.

[67] J. Zhao, Z. Zhang, S. Wang, X. Sun, X. Zhang, J. Chen, D. L. Kaplan, X. Jiang, Bone 2009, 45, 517.

[68] H. Li, R. Zhu, L. Sun, Y. Xue, Z. Hao, Z. Xie, X. Fan, H. Fan, Bio. Med. Res. Int. 2014, 2014, 637821.

[69] J. Ming, Z. Jiang, P. Wang, S. Bie, B. Zuo, Mater. Sci. Eng. C, Mater. Biol. Appl. 2015, 51, 287.

[70] J. R. Vetsch, S. J. Paulsen, R. Muller, S. Hofmann, Acta Biomater. 2015, 13, 277.

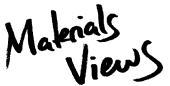

www.MaterialsViews.com
Macromol. Mater. Eng. 2015, 12, 1199-1216

(C) 2015 WILEY-VCH Verlag GmbH \& Co. KGaA, Weinheim 
[71] S. Bai, S. Liu, C. Zhang, W. Xu, O. Lu, H. Han, D. L. Kaplan, H. Zhu, Acta Biomater. 2013, 9, 7806.

[72] M. Li, S. Lu, Z. Wu, H. Yan, J. Mo, L. Wang, J. Appl. Polym. Sci. 2001, 79, 2185

[73] L. Bai, K. Zhan, O. Hu, J. Xu, J. Mater. Sci. Mater. Med. 2014, 25, 1275.

[74] K. Zhang, Y. Qian, H. Wang, L. Fan, C. Huang, X. Mo, J. Biomater. Sci., Polym. Ed. 2011, 22, 1069.

[75] C. Zhao, J. Yao, H. Masuda, R. Kishore, T. Asakura, Biopolymers 2003, 69, 253.

[76] J. M. Yao, H. Masuda, C. Zhao, T. Asakura, Macromolecules $2002,35,6$

[77] A. Vasconcelos, G. Freddi, A. Cavaco-Paulo, Biomacromolecules 2008, 9, 1299.

[78] R. Nazarov, H. J. Jin, D. L. Kaplan, Biomacromolecules 2004, 5, 718.

[79] S. Bhumiratana, W. L. Grayson, A. Castaneda, D. N. Rockwood, E. S. Gil, D. L. Kaplan, G. Vunjak-Novakovic, Biomaterials 2011, 32, 2812.

[80] Y. Pei, X. Liu, S. Liu, O. Lu, J. Liu, D. L. Kaplan, H. Zhu, Acta Biomater. 2015, 13, 168.

[81] Y. Yang, Y. Zhao, Y. Gu, X. Yan, J. Liu, F. Ding, X. Gu, Polym. Degrad. Stab. 2009, 94, 2213.

[82] E. Bellas, K. G. Marra, D. L. Kaplan, Tissue Eng. Part C, Methods 2013, 19, 745.

[83] V. Karageorgiou, M. Tomkins, R. Fajardo, L. Meinel, B. Snyder, K. Wade, J. Chen, G. Vunjak-Novakovic, D. L. Kaplan, J. Biomed. Mater. Res. A 2006, 78, 324.

[84] Z. -H. Li, S. -C. Ji, Y. -Z. Wang, X. -C. Shen, H. Liang, Front. Mater. Sci. 2013, 7, 237

[85] S. Shang, L. Zhu, J. Fan, Carbohydr. Polym. 2013, 93, 561.

[86] J. D. White, S. Wang, A. S. Weiss, D. L. Kaplan, Acta Biomater. $2015,14,1$

[87] S. Shang, L. Zhu, J. Fan, Carbohydr. Polym. 2011, 86, 462.

[88] H. Yoon, E. Y. Kim, H. Kim, C. H. Park, C.-K. Joo, G. Khang, Macromol. Res. 2014, 22, 297.

[89] J.-G. Zhang, X.-M. Mo, Front. Mater. Sci. 2013, 7, 129.

[90] S. Zarkoob, R. K. Eby, D. H. Reneker, S. D. Hudson, D. Ertley, W. W. Adams, Polymer 2004, 45, 3973.

[91] T. Yucel, P. Cebe, D. L. Kaplan, Biophys. J. 2009, 97, 2044

[92] X. Wang, J. A. Kluge, G. G. Leisk, D. L. Kaplan, Biomaterials 2008, 29, 1054.

[93] G. Abdelbary, M. Haider, Pharm. Dev. Technol. 2013, 18, 1159.

[94] S. Yodmuang, S. L. McNamara, A. B. Nover, B. B. Mandal, M. Agarwal, T. A. Kelly, P. H. Chao, C. Hung, D. L. Kaplan, G. Vunjak-Novakovic, Acta Biomater. 2015, 11, 27

[95] U. J. Kim, J. Park, C. Li, H. J. Jin, R. Valluzzi, D. L. Kaplan, Biomacromolecules 2004, 5, 786.

[96] G. -D. Kang, J. -H. Nahm, J. -S. Park, J. -Y. Moon, C. -S. Cho, J. -H. Yeo, Macromol. Rapid Commun. 2000, 21, 788.

[97] T. Hanawa, A. Watanabe, T. Tsuchiya, R. Ikoma, M. Hidaka, M. Sugihara, Chem. Pharm. Bull. 1995, 43, 284.

[98] H. Zhao, S. Xiong, M. Li, O. Zhang, G. Liu, Adv. Mater. Sci. Eng. 2012, 2012, 1.

[99] C. Li, T. Luo, Z. Zheng, A. R. Murphy, X. Wang, D. L. Kaplan, Acta Biomater. 2015, 11, 222.

[100] X. Wang, B. Partlow, J. Liu, Z. Zheng, B. Su, Y. Wang, D. L. Kaplan, Acta Biomater. 2015, 12, 51.

[101] X. Wu, J. Hou, M. Li, J. Wang, D. L. Kaplan, S. Lu, Acta Biomater. 2012, 8, 2185.

[102] L.-P. Yan, A. L. Oliveira, J. M. Oliveira, D. R. Pereira, R. A. Sousa, R. L. Reis, Hydrogels derived from silkfibroin: Methods and uses there of. 06-12-2011, A Portuguese (PT) provisional patent, number 20111000093573 (2011). INPI, Portugal.
[103] R. R. Mallepally, M. A. Marin, M. A. McHugh, Acta Biomater. 2014, 10, 4419.

[104] Z. Ekemen, Z. Ahmad, E. Stride, D. Kaplan, M. Edirisinghe, Biomacromolecules 2013, 14, 1412.

[105] P. Monti, G. Freddi, A. Bertoluzza, N. Kasai, M. Tsukada, J. Raman Spectrosc. 1998, 29, 297.

[106] A. Motta, L. Fambri, C. Migliaresi, Macromol. Chem. Phys. 2002, 203, 1658.

[107] M. Tsukada, Y. Gotoh, M. Nagura, N. Minoura, N. Kasai, G. Freddi, J. Polym. Sci., Part B 1994, 32, 961.

[108] C. Dicko, J. M. Kenney, D. Knight, F. Vollrath, Biochemistry 2004, 43, 14080.

[109] X. Wang, E. Wenk, A. Matsumoto, L. Meinel, C. Li, D. L. Kaplan, J. Control. Release 2007, 117, 360.

[110] H. J. Jin, D. L. Kaplan, Nature 2003, 424, 1057.

[111] F. Xie, H. Zhang, H. Shao, X. Hu, Int. J. Biol. Macromol. 2006, 38, 284.

[112] X. Hu, K. Shmelev, L. Sun, E. S. Gil, S. H. Park, P. Cebe, D. L. Kaplan, Biomacromolecules 2011, 12, 1686.

[113] X. Huang, S. Fan, A. I. M. Altayp, Y. Zhang, H. Shao, X. Hu, M. Xie, Y. Xu, J. Nanomater. 2014, 2014, 1.

[114] B. M. Min, L. Jeong, K. Y. Lee, W. H. Park, Macromol. Biosci. 2006, 6, 285.

[115] J. Jin Nam, Y. H. Park, J. Appl. Polym. Sci. 2001, 81, 3008.

[116] Z. Cao, J. Wen, J. Yao, X. Chen, Y. Ni, Z. Shao, Mater. Sci. Eng. C, Mater. Biol. Appl. 2013, 33, 3522.

[117] S. Hofmann, H. Hagenmuller, A. M. Koch, R. Muller, G. Vunjak-Novakovic, D. L. Kaplan, H. P. Merkle, L. Meinel, Biomaterials 2007, 28, 1152.

[118] D. Marolt, A. Augst, L. E. Freed, C. Vepari, R. Fajardo, N. Patel, M. Gray, M. Farley, D. Kaplan, G. Vunjak-Novakovic, Biomaterials 2006, 27, 6138.

[119] S. Hofmann, K. S. Stok, T. Kohler, A. J. Meinel, R. Muller, Acta Biomater. 2014, 10, 308.

[120] M. A. de Moraes, R. F. Weska, M. M. Beppu, J. Biomed. Mater. Res. Part B, Appl. Biomater. 2014, 102, 869

[121] Y. Zhao, X. Yan, F. Ding, Y. Yang, X. Gu, J. Biomed. Sci. Eng. 2011, 4, 397.

[122] H. Tomoko, T. Yuki, K. Tsunenori, T. Yasushi, K. Hiromichi, Polym. Degrad. Stab. 2015, 112, 20.

[123] S. Asha, Y. Sangappa, P. Naik, K. S. Chandra, G. Sanjeev, AIP Conf. Proc. 2014, 1591, 219.

[124] L. Jeong, I. S. Yeo, H. N. Kim, Y. I. Yoon, H. Jang da, S. Y. Jung, B. M. Min, W. H. Park, Int. J. Biol. Macromol. 2009, 44, 222.

[125] S. C. Jin, H. S. Baek, Y. I. Woo, M. H. Lee, J.-S. Kim, J.-C. Park, Y. H. Park, D. K. Rah, K.-H. Chung, S. J. Lee, I. H. Han, Macromol. Res. 2009, 17, 703.

[126] P. Amornsudthiwat, R. Mongkolnavin, S. Kanokpanont, J. Panpranot, C. S. Wong, S. Damrongsakkul, Colloids Surf. B 2013, 111, 579.

[127] H. U. Poll, U. Schladitz, S. Schreiter, Surf. Coat. Tech. 2001, 142-144, 489

[128] J. Gu, X. Yang, H. Zhu, Mater. Sci. Eng. C. 2002, 20, 199.

[129] Y. Jianwei, D. Yu, S. Zhengzhong, Acta Chim. Sin. 2014, $72,51$.

[130] A. Sionkowska, A. Planecka, K. Lewandowska, M. Michalska, J. Photochem. Photobiol. B 2014, 140, 301.

[131] S. Sofia, M. B. McCarthy, G. Gronowicz, D. L. Kaplan, J. Biomed. Mater. Res. 2001, 54, 139.

[132] T. Kardestuncer, M. B. McCarthy, V. Karageorgiou, D. Kaplan, G. Gronowicz, Clin. Orthop. Relat. Res. 2006, 448, 234.

[133] E. S. Gil, B. B. Mandal, S. H. Park, J. K. Marchant, F. G. Omenetto, D. L. Kaplan, Biomaterials 2010, 31, 8953. 
[134] J. Chen, G. H. Altman, V. Karageorgiou, R. Horan, A. Collette, V. Volloch, T. Colabro, D. L. Kaplan, J. Biomed. Mater. Res. A 2003, 67, 559.

[135] V. Karageorgiou, L. Meinel, S. Hofmann, A. Malhotra, V. Volloch, D. Kaplan, J. Biomed. Mater. Res. A 2004, 71, 528.

[136] S. Hofmann, M. Hilbe, R. J. Fajardo, H. Hagenmuller, K. Nuss, M. Arras, R. Muller, B. von Rechenberg, D. L. Kaplan, H. P. Merkle, L. Meinel, Eur. J. Pharm. Biopharm. 2013, 85, 119.

[137] M. A. Serban, J. A. Kluge, M. M. Laha, D. L. Kaplan, Biomacromolecules 2010, 11, 2230.

[138] C. P. Vepari, D. L. Kaplan, Biotechnol. Bioeng. 2006, 93, 1130.

[139] K. Cai, K. Yao, S. Lin, Z. Yang, X. Li, H. Xie, T. Qing, L. Gao, Biomaterials 2002, 23, 1153

[140] Z. Grabarek, J. Gergely, Anal. Biochem. 1990, 185, 131.

[141] J. P. Lopez-Alonso, F. Diez-Garcia, J. Font, M. Ribo, M. Vilanova, J. M. Scholtz, C. Gonzalez, F. Vottariello, G. Gotte, M. Libonati, D. V. Laurents, Bioconjugate Chem. 2009, 20, 1459.

[142] H. Zhao, E. Heusler, G. Jones, L. Li, V. Werner, O. Germershaus, J. Ritzer, T. Luehmann, L. Meinel, J. Struct. Biol. 2014, 186, 420.

[143] Y. Gotoh, M. Tsukada, N. Minoura, Y. Imai, Biomaterials 1997, 18, 267.

[144] Y. Gotoh, S. Niimi, T. Hayakawa, T. Miyashita, Biomaterials 2004, 25, 1131.

[145] Y. Gotoh, M. Tsukada, S. Aiba, N. Minoura, Int. J. Biol. Macromol. 1996, 18, 19.

[146] T. Furuzono, K. Ishihara, N. Nakabayashi, Y. Tamada, Biomaterials 2000, 21, 327.

[147] A. Vasconcelos, A. C. Gomes, A. Cavaco-Paulo, Acta Biomater. 2012, 8, 3049

[148] Y. O. Zhang, Y. Ma, Y. Y. Xia, W. D. Shen, J. P. Mao, X. M. Zha, K. Shirai, K. Kiguchi, J. Biomed. Mater. Res. Part B, Appl. Biomater. 2006, 79, 275.

[149] K. Zhang, Y. Oian, H. Wang, L. Fan, C. Huang, A. Yin, X. Mo, J. Biomed. Mater. Res. A 2010, 95, 870

[150] E. T. Baran, K. Tuzlakoglu, J. F. Mano, R. L. Reis, Mater. Sci. Eng. C, Mater. Biol. Appl. 2012, 32, 1314.

[151] Y. Gotoh, M. Tsukada, N. Minoura, Int. J. Biol. Macromol. 1992, 14, 198.

[152] Y. Gotoh, M. Tsukada, N. Minoura, Int. J. Biol. Macromol. 1996, 19, 41

[153] P. Taddei, C. Arosio, P. Monti, M. Tsukada, T. Arai, G. Freddi, Biomacromolecules 2007, 8, 1200 .

[154] H. Liu, X. Li, G. Zhou, H. Fan, Y. Fan, Biomaterials 2011, 32, 3784.

[155] H. Liu, X. Li, X. Niu, G. Zhou, P. Li, Y. Fan, Biomacromolecules 2011, 12, 2914.

[156] X. Liu, W. Xu, C. Zhang, H. Liu, J. Fang, Mater. Lett. 2015, 143 , 302.

[157] T. J. Mason, D. Peters, Practical Sonochemistry: Power Ultrasound Uses and Applications. 2nd edition, Woodhead Publishing, Chischester 2002.

[158] T. J. Mason, Advances in Sonochemistry. 1st edition, JAI Press, Stamford 1999, Vol. 5

[159] J. H. Bang, K. S. Suslick, Adv. Mater. 2010, 22, 1039.

[160] U. Shimanovich, G. J. L. Bernardes, T. P. J. Knowles, A. CavacoPaulo, Chem. Soc. Rev. 2014, 43, 1361.

[161] R. Silva, H. Ferreira, N. G. Azoia, U. Shimanovich, G. Freddi, A. Gedanken, A. Cavaco-Paulo, Molecular Pharmaceutics 2012, 9, 3079.

[162] D. L. Kaplan, T. Yucel, X. Wang, M. Lovett, Methods and compositions for preparing a silk microsphere. Google Patents, 2013

[163] M. L. Lovett, X. Wang, T. Yucel, L. York, M. Keirstead, L. Haggerty, D. L. Kaplan, Eur. J. Pharm. Biopharm. 2015, doi: 10.1016/j.ejpb.2014.12.029.
[164] H. Y. Wang, Y. Y. Chen, Y. O. Zhang, Mater. Sci. Eng. C, Mater. Biol. Appl. 2015, 48, 444.

[165] X. Wang, E. Wenk, X. Zhang, L. Meinel, G. Vunjak-Novakovic, D. L. Kaplan, J. Control. Release 2009, 134, 81.

[166] D. Huang, L. Wang, Y. Dong, X. Pan, G. Li, C. Wu, Eur. J. Pharm. Biopharm. 2014, 88, 104.

[167] E. Wenk, A. J. Wandrey, H. P. Merkle, L. Meinel, J. Control. Release 2008, 132, 26.

[168] X. Wang, T. Yucel, O. Lu, X. Hu, D. L. Kaplan, Biomaterials 2010, 31, 1025

[169] K. Shang, J. Rnjak-Kovacina, Y. Lin, R. S. Hayden, H. Tao, D. L. Kaplan, Transl. Vis. Sci. Technol. 2013, 2, 2.

[170] R. L. Horan, K. Antle, A. L. Collette, Y. Wang, J. Huang, J. E. Moreau, V. Volloch, D. L. Kaplan, G. H. Altman, Biomaterials 2005, 26, 3385.

[171] M. Li, M. Ogiso, N. Minoura, Biomaterials 2003, 24, 357.

[172] L. Wang, R. Nemoto, M. Senna, J. Nanopart. Res. 2004, 6, 91.

[173] S. K. Samal, M. Dash, F. Chiellini, D. L. Kaplan, E. Chiellini, Acta Biomater. 2013, 9, 8192.

[174] K. Numata, P. Cebe, D. L. Kaplan, Biomaterials 2010, 31, 2926

[175] Y. Suzuki, H. Matsui, Y. Tsujimoto, K. Watanabe, J. Biosci. Bioeng. 2009, 108, 211.

[176] K.-J. Park, H.-H. Jin, C.-K. Hyun, Process Biochem. (Oxford, U K) 2002, 38, 411.

[177] E. S. Gil, S.-H. Park, X. Hu, P. Cebe, D. L. Kaplan, Macromol. Biosci. 2014, 14, 257.

[178] S. Sampaio, P. Taddei, P. Monti, J. Buchert, G. Freddi, J. Biotechnol. 2005, 116, 21.

[179] G. Freddi, A. Anghileri, S. Sampaio, J. Buchert, P. Monti, P. Taddei, J. Biotechnol. 2006, 125, 281.

[180] G. D. Kang, K. H. Lee, C. S. Ki, J. H. Nahm, Y. H. Park, Macromol. Res. 2004, 12, 534.

[181] P. Monti, G. Freddi, S. Sampaio, M. Tsukada, P. Taddei, J. Mol. Struct. 2005, 744-747, 685

[182] P. Wang, Y. Zhou, L. Cui, J. Yuan, O. Wang, X. Fan, Y. Ding Fibers Polym. 2014, 15, 2045

[183] V. P. Ribeiro, J. Silva-Correia, V. Gonçalves-Miranda, L.-P. Yan A. L. Oliveira, R. M. Reis, J. M. Oliveira, R. L. Reis, Smart silk fibroin hydrogels and its potential application as suppressor of angiogenesis and tumor progression. http://www.3bs. uminho.pt/content/smart-silk-fibroin-hydrogels-and-itspotential-application-suppressor-angiogenesis-and-tumor.

[184] Z. Chen, M. Kimura, M. Suzuki, Y. Kondo, K. Hanabusa, H. Shirai, Fiber 2003, 59, 168.

[185] Z. Chen, M. Kimura, M. Suzuki, H. Tsuiki, Y. Kondo, K. Hanabusa, H. Shirai, Fiber 2004, 60, 81.

[186] Z. Chen, M. Suzuki, M. Kimura, Y. Kondo, K. Hanabusa, H. Shirai, J. Appl. Polym. Sci. 2004, 92, 1540.

[187] S. K. Samal, M. Dash, H. A. Declercq, T. Gheysens, J. Dendooven, P. Van Der Voort, R. Cornelissen, P. Dubruel, D. L. Kaplan, Macromol. Biosci. 2014, 14, 991.

[188] S. Winkler, D. Wilson, D. L. Kaplan, Biochemistry 2000, 39, 14002.

[189] V. Volkov, A. Vasconcelos, M. P. Sarria, A. C. Gomes, A. Cavaco-Paulo, Biotechnol. J. 2014, 9, 1267

[190] V. Volkov, M. P. Sarria, A. C. Gomes, A. Cavaco-Paulo, Mol. Pharmaceutics 2015, 12, 75.

[191] J. Liu, B. D. Lawrence, A. Liu, I. R. Schwab, L. A. Oliveira, M. I. Rosenblatt, Invest Ophthalmol. Vis. Sci. 2012, 53, 4130.

[192] T. L. Liu, J. C. Miao, W. H. Sheng, Y. F. Xie, O. Huang, Y. B. Shan, J. C. Yang, J. Zhejiang, Univ. Sci. B 2010, 11, 10.

[193] K. Tsubouchi, H. Nakao, Y. Igarashi, Y. Takasu, H. Yamada, J. Insect Biotechnol. Sericol. 2003, 72, 65.

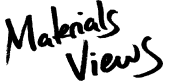

www.MaterialsViews.com
Macromol. Mater. Eng. 2015, 12, 1199-1216

(c) 2015 WILEY-VCH Verlag GmbH \& Co. KGaA, Weinheim 
[194] M. D. Tang-Schomer, X. Hu, M. Tupaj, L. W. Tien, M. Whalen, F. Omenetto, D. L. Kaplan, Adv. Funct. Mater. 2014, 24, 1938.

[195] F. Zhang, X. You, H. Dou, Z. Liu, B. Zuo, X. Zhang, ACS Appl. Mater. Interfaces 2015, 7, 3352.

[196] O. Lu, X. Hu, X. Wang, J. A. Kluge, S. Lu, P. Cebe, D. L. Kaplan, Acta Biomater. 2010, 6, 1380.

[197] C. Zhang, D. Song, O. Lu, X. Hu, D. L. Kaplan, H. Zhu, Biomacromolecules 2012, 13, 2148.

[198] K. Wei, B. S. Kim, I. S. Kim, Membranes 2011, 1, 275.

[199] Z. Liu, F. Zhang, J. Ming, S. Bie, J. Li, B. Zuo, J. Appl. Polym. Sci. 2014, 132, 41236.

[200] A. Matsumoto, J. Chen, A. L. Collette, U. J. Kim, G. H. Altman, P. Cebe, D. L. Kaplan, J. Phys. Chem. B 2006, 110, 21630.

[201] M. Ribeiro, M. A. de Moraes, M. M. Beppu, M. P. Garcia, M. H. Fernandes, F. J. Monteiro, M. P. Ferraz, Eur. Polym. J. 2015, 67, 66.

[202] N. A. Guziewicz, A. J. Massetti, B. J. Perez-Ramirez, D. L. Kaplan, Biomaterials 2013, 34, 7766.

[203] S. -M. Bai, W. -M. Zhang, O. Lu, O.-H. Ma, D. L. Kaplan, H. Zhu, J. Mater. Chem. B 2014, 2, 6590 .

[204] R. Elia, D. R. Newhide, P. D. Pedevillano, G. R. Reiss, M. A. Firpo, E. W. Hsu, D. L. Kaplan, G. D. Prestwich, R. A. Peattie, J. Biomater. Appl. 2013, 27, 749.

[205] K. Numata, S. Yamazaki, T. Katashima, J.-A. Chuah, N. Naga, T. Sakai, Macromol. Biosci. 2014, 14, 799.

[206] S. Bai, X. Zhang, O. Lu, W. Sheng, L. Liu, B. Dong, D. L. Kaplan, H. Zhu, Biomacromolecules 2014, 15, 3044.

[207] E. Bellas, T. J. Lo, E. P. Fournier, J. E. Brown, R. D. Abbott, E. S. Gil, K. G. Marra, J. P. Rubin, G. G. Leisk, D. L. Kaplan, Adv. Healthcare Mater. 2015, 4, 452.

[208] A. J. Heard, S. Socrate, K. A. Burke, E. R. Norwitz, D. L. Kaplan, M. D. House, Reprod. Sci. 2013, 20, 929.
[209] M. Lovett, C. Cannizzaro, L. Daheron, B. Messmer, G. VunjakNovakovic, D. L. Kaplan, Biomaterials 2007, 28, 5271.

[210] T. Yucel, M. L. Lovett, R. Giangregorio, E. Coonahan, D. L. Kaplan, Biomaterials 2014, 35, 8613.

[211] P. C. DeMuth, Y. Min, D. J. Irvine, P. T. Hammond, Adv. Healthcare Mater. 2014, 3, 47.

[212] J. Lee, S. H. Park, I. H. Seo, K. J. Lee, W. Ryu, Eur. J. Pharm. Biopharm. 2015, 94, 11.

[213] W. K. Raja, S. Maccorkle, I. M. Diwan, A. Abdurrob, J. Lu, F. G. Omenetto, D. L. Kaplan, Small 2013, 9, 3704.

[214] R. Rajkhowa, A. Kafi, O. T. Zhou, A. Kondor, D. A. V. Morton, X. Wang, Powder Technol. 2015, 270, Part A, 112.

[215] R. Rajkhowa, X. Hu, T. Tsuzuki, D. L. Kaplan, X. Wang, Biomacromolecules 2012, 13, 2503.

[216] M. Kazemimostaghim, R. Rajkhowa, K. Patil, T. Tsuzuki, X. Wang, Powder Technol. 2014, 254, 488.

[217] T. K. Mwangi, R. D. Bowles, D. M. Tainter, R. D. Bell, D. L. Kaplan, L. A. Setton, Int. J. Pharm. 2015, 485, 7.

[218] W. Zhou, Y. Feng, J. Yang, J. Fan, J. Lv, L. Zhang, J. Guo, X. Ren, W. Zhang, J. Mater. Sci. Mater. Med. 2015, 26, 5386.

[219] Y. G. Chung, D. Tu, D. Franck, E. S. Gil, K. Algarrahi, R. M. Adam, D. L. Kaplan, C. R. Estrada, Jr., J. R. Mauney, PLoS ONE 2014, 9, e91592.

[220] S. Lin, G. Lu, S. Liu, S. Bai, X. Liu, O. Lu, B. Zuo, D. L. Kaplan, H. Zhu, J. Mater. Chem. B, Mater. Biol. Med. 2014, 2, 2622.

[221] G. Lu, S. Liu, S. Lin, D. L. Kaplan, O. Lu, Colloids Surf. B 2014, 120, 28.

[222] Z. Fan, F. Zhang, T. Liu, B. O. Zuo, Int. J. Biol. Macromol. 2014, 65, 516.

[223] Z. Zhao, Y. Li, M. B. Xie, Int. J. Mol. Sci. 2015, 16, 4880.

[224] D. I. Pattison, A. S. Rahmanto, M. J. Davies, Photochem. Photobiol. Sci. 2011, 2012, 38. 